\title{
Beiträge zur
}

Kritik dèr I)arwin'schen Lehre.

Gesammelte und vermehrte Abhandlungen

soll

Gustav Wolff

Dr. med. et phil.

- Privatdozent in Wiirzburg.

L E I P Z I G.

Verlag ron Arthur Georgi.

1898. 
Digitized by the Internet Archive in 2020 with funding from University of Toronto 


\section{Vor l w o l t.}

Mehrfach mir zugegangener Aufforderung komme ich nach, wemn ich hiermit meine im ,Biologischen Centralblatt” elschienenen Aufsätze zur Kritik der Darwinschen Lehre gesondert herausgebe. Wäre es nach meinem Wunsche gegangen, so würden diese Aufsätze iiberhaupt nicht in einer Fachzeitschrift, sondern gleich im Buchhandel erschienen sein. Aber vor acht Jahren lagen die Verhältnisse eben noch ander's als hente. Damals erschien das Dogma der Zuchtwahllehre noch so unantastbar, dass kein Verleger sich getranen wollte, meine Arbeit in Verlag zu nehmen.

Unterdessen haben sich gliicklicherweise die Zeiten geändert. Es bricht sich zweifellos allmählich die Erkemntnis Bahn, dass es mit dem Darwinismus eine arge Täuschung gewesen ist, und man sucht ihn möglichst anständig wieder loszuwerden oder auch möglichst unanständig, indem man \%. B. thut, als habe es iln nie gegeben. Ja, in den Reihen seiner Gegner zeigen sich jetzt schon einzehe jener weisen Naturen, die bei wichtigen Fragen, so lange diese noch schweben, in vorsichtiger Reserve bleiben und sich nicht „engagieren“, wie der köstliche Ausdruck lautet, die aber, sobald der Ausgang: des Kampfes nicht mehr zweifelhaft ist, mit der siegenden Fahne voranstïrmen, $11 \mathrm{~m}$ sich rasch noch in der "Geschichte" ein Denkmal zu setzen.

Das Ende der Darwinistischen Herrschaft, welches durch derartige Zeichen vielleicht am dentlichsten verkündigt wird, muss 
aber, wenn es einen wirklichen Fortschritt bedeuten soll. auch die entsprechenden Konsequenzen mach sich ziehen. Nicht nur ein negatives, sondern vor allem ein positives Ergebnis soll gewonnen werden. Die Wissenschaft muss das ihr durch die Darwinistische Epoche entrissene Hauptproblem wiedergewinnen. Denn es handelt sich nicht, wie jetzt uns manche glauben machen wollen, um die Frage nach dem grösseren oder kleineren Anteil, welcher neben andern Faktoren dem Selektionsprinzip zur mechanischen Erklärung der organischen Zweckmässigkeit zugesprochen werden soll, sondern es handelt sich um die Frage, ob die Zweckmässigkeit mechanisch erklärt werden kann, bzw. um die Anerkennung der Thatsache, dass bis jetzt alle diese Versuche gescheitert sind, und dass die mechanische Erklärbarkeit der organischen Zweckmässigkeit lediglich als Dogma der alleinseligmachenden mechanischen Weltanffassung dasteht, und deshalb ebensowenig wie jedes audere Dogma eine wissenschaftliche Existenzberechtigung hat.

Diese biologische Kardinalfrage aber, ob zum Verständnis der organischen Vorgänge die Prinzipien der Mechanik ausreichen, oder ob es einen teleologisch zu benrteilenden Faktor, eine primäre Zweckmässigkeit giebt, ist vou grundlegender Bedentung für alle biologischen Disziplinen, besonders auch für dasjenige Gebiet, welches das höchste Problem des Lebens behandelt, und deshalb mit Recht in der nenesten Zeit in den Vordergrund des Interesses zu treten beginnt, in der Psychologie. Hier wird die Selektionstheorie vielfach noch mit einer geradezu rührenden Sicherheit gehandlıabt. Diesen Darwinistischen Autoritätsglauben auch auf denjenigen biologischen Gebieten zu bekämpfen, deren Vertreter häufig glauben, ihre Grundprinzipien auf Treu und Glauben von andern annehmen zu dürfen - ohne sich dabei klar zu machen, von wem -, ist der Hauptwunsch, der mich veranlasst, diese Aufsätze einem grösseren Leserkreise als demjenigen einer Fachzeitschrift zugänglich zu machen.

Weggelassen wurden bei diesem Neudruck die beiden letzten Sätze der dritten Abhandlung, und neu hinzugekommen 
sind das IX. Kapitel der ersten Abhandlung („Die geschlechtliche Znchtwahl"), die drei letzten Absätze der dritten Abhandlung und die mit sternchen (*) bezeichneten Anmerkmngen.

Weitere Ansfïhrungen iiber die hier behandelten Gegenstände finden sich in meinen bei Engelmann in Leipzig erschienenen Schriften: „Der gegenwärtige Stand des Darwinismus“ und „Zur Psychologie des Erkemnens".

Würzburg im Mär\% 1898. 



\section{Erste Abhandlung*).}

\section{Einleitung.}

Die Bedeutung einer mechanischen Erklärung der in der belebten Natur sich offenbarenden Zweckmässigkeit ist so einlenchtend, dass darüber kein Wort zu verlieren ist. Der von Darwin durch seine Selektionstheorie gemachte und zur Zeit fast allgemein als gelungen betrachtete Erklärungsversuch wird denn auch als eine der grössten geistigen Errungenschaften angesehen. Niemand wird lenguen, dass muter Voraussetzung der Richtigkeit der Darwinschen Lehre die derselben beigelegte epochemachende Bedeutung volle Berechtigmng hat. Aber ans der Bedentung, welche diese Lehre besitzt, wenn sie richtig ist, erhellt zugleich die Bedentung, welche ihr innewohnt, wenn sie falsch ist. Denn diese Bedeutung ist dam nicht wu gleich Null, sondern gleich einer negativen Grösse, deren absoluter Wert demjenigen gleichkommt, den die positive Grösse besitzt, durch welche die Bedentuug der Selektionstheorie bezeichnet wird, wenn sie richtig ist. Das heisst: je grösser der Gewimn ist, welchen diese Lehre in ersten Falle mit sich bringt, um so grösser ist der Verlust, del sie im zweiten Falle begleitet, weil sie uns damn ja um ebensoviel von unserem Ziele weg, als im ersten Fall demselben nüher führen wird. Da nun die Richtigkeit der Selektionstheorie nicht bewiesen ist, so kann auch nicht mit Bestimmtheit

“) Erschienen im „Biolog. Centralblatt" vom 15. September 1890. WVolff, Beitrïge zur Kritik der Marwinschen Lchre. 
angegeben werden, ob diese Lehre den ersten, überaus fruchtbaren, oder den andern überaus verderblichen Einfluss auf unser Erkemmen ausuibt.

Das Bestechende der Selektionstheorie, dasjenige, was ihr in so kurzer Zeit die allgemeine Herrschaft erobert hat, ist die scheimbar mathematische Exaktheit, mit welcher aus ihren Voranssetzungen, deren Richtigkeit ganz unbestreitbar ist, die Entstehmng zweckmässiger Einrichtungen gefolgert werden kann.

Variierung und Überproduktion, die beiden Voraussetzungen der Theorie, sind zwei gegebene Thatsachen, und aus ihnen scheint mit logischer Notwendigkeit die Auslese des Bessel'n im Kampf ums Dasein zu folgen.

Die Mehrzahl unserer Naturforscher begnïgte sich num mit der Einsicht, dass die Selektionstheorie das Zustandekommen zweckmässiger Einrichtungen erkläre. Sie hielten damit das grosse Rätsel für gelöst und übersahen, dass es sich darum handelt, nicht ob diese Theorie die Entstehung zweckmässiger Einrichtungen überhaupt, sondern ob sie die Entstehung der ganz bestimmten, in der Natur vorhandenen, zweckmässigen Eimrichtungen zl، erklären im stande ist. Obwohl wir, die wir uns für Empiriker ansgeben, uns so oft unserer induktiven Nethode rühmen und das erfahrungsmässige Wissen als das alleinseligmachende hinstellen, begnügen wir uns hier in seltsam ironischem Widerspruch zu den von uns zur Schau getragenen Grundsätzen mit einer unabhängig von der Erfahrung konstruierten 'Theorie und verzichten oder besser vergessen, diese auf einem dem induktiven völig entgegengesetzten Wege gewonnene Theorie wenigstens nachträglich zur Prüfung ihrer Richtigkeit mit den Gegenständen der Erfahrung zu vergleichen, eine Kurzsichtigkeit, die $u$ m so unbegreiflicher erscheint, als man sich bei nur einigermassen grïndlicher Betrachtung der Sache sagen musste, dass eine solche Vergleichung gerade in diesem Falle ganz besonder's und zwar in dem grösstmöglichen Umfange nötig gewesen wäre.

Denn wenn ibberhaupt von jeder Theorie zu wünschen ist, dass sie die in Frage stehenden Erscheinungen vollständig 
erkläre, so muss gerade von einer solchen, die es sich zur Aufgabe macht, die Zweckmässigkeit in der organischen Natur zu erklären, eine völlig mniverselle Giltigkeit der Erklärung aufs allerentschiedenste gefordert werden. Sobald auch nur von einer einzigen zweckmässigen Einrichtung bewiesen werden kann, dass zu inrer Erklärung die Selehtionstheorie niclıt ausreicht, so ist damit diese 'Theorie geradezu bedeutungslos geworden. Es kommt ihr dam nicht das für sie in Anspruch genommene Verdienst zu, die Zweckmässigkeit ,.ihres transzendentalen Charakters entkleidet." zu haben. Denn wenn gezeigt ist, dass ausser der Selektion ein anderer das zweckmässige gestaltende Falitor existieren muss, so wissen wir ju nicht, ob dieser andere Haktor nicht der einzige und derjenige ist, der auch jene '/weckmässigkeiten, zu deren Erklärung die Selektionstheorie ausreichen wiirde, herrorgebracht laat. Die das Organismenreich in solch einheitlicher Harmonie durchziehende Zweckmässigkeit deutet in so kiarer Weise auf eine einheitliche Ursache, dass wahrlıaftig ein grosser Mangel an philosophischem Denken dazu gehörte, un hier' auf eine 'T'eilung' zu verfallen und die eine Zweckmässigkeit auf diese, die ander'e auf jene Ursache zurïckfüln'en zu wollen.

Wemn also die Selektionstheorie nicht Alles erklärt, so erklärt sie nichts. Ein einziges Beispiel ron Zweckmässigkeit, das durch sie nicht erklärt wird, wirft sie über den Haufen.

Über diesen Punkt war sich übrigens Darwin selbst vollkommen klar, demn er hat mehr als eimmal ausdrüicklich hervorgehoben, dass ein einziges nach seiner Lehre unerklärliches Beispiel genïgend sei, die ganze Theorie umzustossen.

\section{Das Variierungsinkrement, das die Selektionstheorie voraus- setzen darf, muss ein Differential sein.}

Die in der Selektionstheorie liegende Erklärung bestelıt ja darin, dass sie das Komplizierte eben nicht schon voraussetzt, sondern hervorgehen lässt aus Anfängen und Inkrementen, die man sich so einfach vorstellen darf, als man nur irgend will. Damit führt die 'Theorie, wie dies schon mehrfach aus- 
gesprochen wurde, den Begriff des Differentials in die biologische Wissenschaft ein und ist in Stande, aus der Summation, aus der Integration dieser Differentialien schliesslich ein sehr kompliziertes Resultat abzuleiten. Aber, wohlgemerkt, der Zuwachs, den die Selektionstheorie für die einzelnen Generationen fordern darf, muss auch wirklich ein Differential sein, d.h. die Theorie muss zu ihrem Resultate kommen, sie mag ihn so klein annehmen, als sie will, denn sie hat kein Recht, von der Variierung etwas anderes als völlige Regellosigkeit zu erwarten. Nur solche Einrichtungen, die ich mir aus einer Summe von Inkrementen hervorgegangen denken kamm, über deren Grösse ich keinerlei Voraussetzung zu machen brauche, nur solche Einrichtungen fallen in das Erklärungsgebiet der Selektionstheorie. Muss dagegen für die einzelnen Inkremente schon ein bestimmter Grad von Regelmässigkeit und Kompliziertheit angenommen werden, so ist die Selektionstheorie unbrauchbar, weil sie ja damn das, was sie erklären will, schon voraussetzen würde.

Ein Beispiel wird die Sache am klarsten machen. Das Wirbeltierauge ist eine äusserst komplizierte Einrichtung; aber man kann sich seine phylogenetische Entstehung als eine Summation von ungeheuer vielen Inkrementen denken,. für deren Komplikationsgrad man jede noch so kleine Grösse annehmen kann. Wir denken uns also z. B., dass durch zufällige Variierung ein ganz minimaler Pigmentfleck bëi einem Tiere erschien. Es kann mit völliger Sicherheit behauptet werden dass vermöge der Variierung die Pigmentflecke der Kinder des 'Tieres einander nicht ganz gleich waren, sondern bei dem einen etwas grösser, bei dem andern etwas kleiner. Wir mögen die Unterschiede so klein annehmen, als wir wollen: aus der Summation der jed̉esmal ausgewählten grössten Pigmentflecke resultiert ein Pigmentfleck, dessen Grösse von der Zahl der' Summationselemente, also der Generationen, abhäng't. Da aber die Theorie diese Zahl beliebig gross annehmen darf, so kann sie aus jenem Pigmentfleck, den sie ebenso wie alle Inkremente so klein, als sie nur irgend wollte, annehmen durfte, einen 
Pigmentfleck von jeder beliebigen Grösse ableiten. Da man sich wohl so ziemlich alle Teile des Auges als eine Summe von solchen Differentialinkrementen denken kann, so kiam man sich nach der Selektionstheorie die Entstehung eines Auges vorstellen.

\section{Es giebt Gebilde, deren Entstehungsinkremente nicht als Differentialien gedacht werden können.}

Nun hat aber das Wirbeltier nicht nur ein, sonder'n zwei Augen; die Entstehung zweier in allen Details übereinstimmender Gebilde von solcher Kompliziertheit kamm nur gedacht werden, indem angenommen wird, dass beide Augen gleich variiert haben, d. h. dass die Varierungsinkremente immer dieselben waren. Hier haben wir also für" unsere Tolaussetzung bezüglich des Tariiermosinkrementes nicht mehr freien spielraum, sondern dieselbe hat eine bestimmte Forderung $\%$ befrierligen. Wir müssen einen ganz bestimmten Komplikationsgrad für jedes einzelne Varierungsinkrement postulieren; diese von uns anzmnehmende Kompliziertheit besteht eben darin, dass jede kleinste Variierung, die sich an einem Auge fand, anch am andern vorhanden war. Da aber die Selektionstheorie für die Erscheinmgen, die sie erklärt, nu dadurch zu einer Erklärung wird, dass sie das Komplizierte aus dem 'ron jeder' Kompliziertheit Freien, dass sie das Regelmässige aus dem Regellosen ableitet, so kann sie hier, wo ihre Toraussetzungen schon die Regel fordern, nicht anwendb) ar sein.

Man wird mir wohl kaum einwenden: Wirbeltiere sind symmetrische 'liere, symmetrische 'Tiere variieren eben symmetrisch. Denn ganz abgesehen daron, dass bei Anmahme eines solchen Gesetzes die primäre symmetrie eben vorausgesetzt aber nicht erklärt wäre, existiert ein Gesetz, wonach symmetrische Tiere nur symmetrisch abändern, überhaupt nicht: das lehrt ein Blick auf eine gefleckte Kuh, das beweisen die Augen der Pleuronektiden, das beweisen alle nicht median gelegenen mparen Organe! 
Im ïbrigen handelt es sich nicht nur um symmetrische Gebilde, sondern z. B. anch um alle homodynamen. Wartum sind die Insektenbeine oft ganz genau gleich? ein Gesetz, wonach segmentale Gebilde gleich variieren müssten, giebt es nicht, denn die Mundwerkzenge haben ja anders variiert.

Man kann diesen Einwand viel weiter fassen. Alle Gebilde, die an demselben Organismus vorhanden und gleich sind, spotten der Erklärung durch die Selektionstheorie. Es ist nach ihr nicht erklärlich, warum bei Raubtieren z. B. zwei Backzähne (derselben Seite) sich im Laufe der phylogenetischen Entwicklung aus kleinen Hantzähnchen zu solchen in allen Details ïbereinstimmenden Gebilden durch zufällige, immer gleiche Variiermng entwickelt haben. Dass ei n Zahn sich durch zufällige Variierung zu einem solch vortrefflichen Trauwerkzenge entwickelt hat, liesse sich ja durch Selektion erklären, weil wir damn eben für die Variierung uur Regelloses vorauszusetzen brauchten; dass aber der nebenstehende immer ganz genan gleich variiert hat, so dass das Resultat dasselbe ist, das lässt sich nicht erklären und dentet darauf hin, dass die Veränderung der Formen von einem Gesetze beher'scht wird, welches wir nicht kennen, welches aber zu erforschen jetzt die vornehmste Aufgabe für alle denkend betriebene Biologie bilden muss.

Solche Erscheinungen, welche der Erklärung durch die Selektionstheorie widerstreben, weil sie hier eine gesetzmässige komplizierte Veränderung der Formen voraussetzen wïrde, statt sie zu erklären, sind aber nicht etwa nur vereinzelte Fïlle, sondern ron solchen wird die ganze Formgestaltung beherrscht, wie z. B. von symmetrischer Anlage. Auch branchen wir uns bei dieser Betrachtung nicht nur anf solche Gebilde zu beschränken, die in geringer Mehrheit vorhanden sind, sondern es giebt ja Gebilde, die in hundert-, ja tausendfacher Anzahl an einem und demselben Organismus sich finden, wie Schuppen, Haare, Federn. Betrachten wir z. B. gerade die Federn. Wie viel Millionen Tariiermgen musste eine Reptilienschuppe durchmachen, bis sie sich in eine Feder ver- 
wandelt hatte, vollends noch in ein so kompliziertes Gebilde wie z. B. die Schwanzfeder des Pfanes. Aber dies wäre immer noch nach der Selektionstleorie erklärlich. Nicht erklärlich dagegen wäre, dass die anderen Schwanzfeder'n immer' gleichzeitig dieselben Variermngen durchmachten. Ein Geset\%, welches ein einlıeitliches Variieren dieser Hautgebilde rorschreibt, giebt es nicht, demn es variieren ja nicht alle gleich. Es entstehen viele gleiche Elaumfedern, viele gleiche Schwanzfedern etc., an einigen Stellen bleiben die Schuppen sogar ellialten, nämlich an den hinteren Extremitäten.

Wir kömen noch weiter gehen. Eine Masse von einzehnen Zellen musste bei den verschiedenen Diff'erenzierungen, bei kntstehung des Darms, des Nervensystems, der Muskulatur etc. in ganz genau der gleichen Weise rarieren. Wem wir hier die Selektionstheorie zur Erklärung herbeizielien wollen. so ist die Kompliziertheit des einzelnen Variierungsinkrementes so gross, dass damit die ganze weitere lirklärung iiberflüssig wird.

Tnteressant sind ferner solclie homodynamen Gebilde, die niclıt zu gleicher Zeit auftreten, wie der dritte halbzirkelförmige Kanal im Gelı̈rorgan der Wirbeltiere, welcher bekamtlich erst in der Klasse der Fische auftritt. Dieser dritte Kanal ist den beiden andern völlig gleicl, hat Crista, Ampulle. Macula etc., ist aber später entstanden; die nämlichen zufälligren Tariierungen, die stattfanden bei der Entstehung der beiden ersten Kanäle, mussten viele Generationen später ganz genau in derselben Art sich wiederlolen! Dass diese Tariierungen wieder auftreten, dies erklärt die Darwinsche Lehre nicht; denn die Selektion kamn ja keinen Einfluss auf die Tariierung ausiiben.

Aehnlich sind die Resultate der Kowalevskyschen Untersuchungen über fossile Huftiere zu betrachten, welche sich auf die im Lauf der phylogenetischen Entwicklung stattgeliabten Umwandlungen des Extremitätenskelettes dieser 'Tiere beziehen. Hier kann bekanntlich eine allmälllich eintretende Verringerung der Anzahl der Metatarsal- und Metakarpalknochen sowie der Phalangen verfolgt werden. Diese Ver- 
ringerung tritt zuerst an den hintern, erst später an den vordern Extremitäten auf!

\section{Fortsetzung.}

Wir betrachten jetzt solche Fälle, bei denen die Selektionstheorie über das Variierungsinkrement nicht wie in den bisher besprochenen Beispielen in der Weise von vornherein verfügen muss, dass sie eine bestimmte Eigentümlichkeit in mehrfacher Zahl für jedes Inkrement fordert, sondern in der Weise, dass sie zu einer bestimmten Eigentiimlichkeit ausnahmslos noch eine weitere bestimmte Eigentümlichkeit für jedes Inkrement voraussetzen muss. Die Zahl solcher Fälle ist Legion.

Betrachten wir z. B. die Beziehungen zwischen Muskeln und Nerven höherer Tiere, so können wir die Entstehung derselben uns nach der Selektionstheorie nur denken, wenn wir von jedem einzelnen Variierungsinkrement eine sehr bedeutende Kompliziertheit voraussetzen. Wir miissen nicht nur annehmen, dass eine Zelle sich durch unzählige Variierungen zu einer Muskelzelle umgebildet hat (was ja denkbar wäre), sondern auch, dass zugleich eine andere Zelle entsprechend sich zu einer Nervenzelle differenzierte, ja dass von vornherein eine Beziehung der beiden Gebilde da war, denn ohne diese wäre beides funktionslos, der Vorteil fiele weg, und Selektion könnte nicht eintreten; diese Kombination müsste aber nicht etwa nur einmal, sondern gleichzeitig in tausendfacher Anzahl an einem Organismus aufgetreten sein. Welche Kompliziertheit miisste hier die Selektion für das einzelne Variierungsinkrement voraussetzen!

Bei Organen, deren Funktion von einem Zentrum regiert wird, können sich Organ und Zentrum nicht unabhängig von einander entwickelt haben. Die Entwicklung eines Auges niitzte nichts, wenn nicht mit ihr die Entwicklung eines Sehzentrums Hand in Hand ging. Ohne das eine hat das andere keinen Sim, keine Bedeutung, weshalb die Selektion sie nicht einzeln hervorbringen konnte. Die gleich zeitig e Entstehung aber von Organ und Zentrum könnte die Selektionstheorie nur 
erklären, wenn sie von den Varierungsinkrementen einen ganz bestimmten Komplikationsgrad voraussetzen, $\mathrm{l}$. l. Wenn sie auf denjenigen Punkt, der allein sie zu einer wirklichen Erklärnng hefähigen könnte, nämlich das voraussetzungslose Tariierungsinkrement, verzichten wïrde.

Diese Art der Komplikation des Tariierungsinkrementes wird vielleicht am dentlichsten, wenn wir solche Gebilde betrachten, deren Gebrauch vom Instinkt abhängt.

So kamn die Selektionstheorie \%. B. die pliylogenetische Entstehung eines Penis nur erkiären, wenn sie zugleich mit ihr die Entstelnung des Instinktes, den richtigen Gebrauch daron zu machen, Hand in Hand gehen lässt. Auch hier liegt. die genau bestimmte Komplikation des Variierungsinkrenentes am 'Tage: zu der zufälligen Variierung, die zur Entstehung des Penis fïhrt, muss eine entsprechende Variierung im \%entralnervensystem treten. So ist es mit allen Instinkten, welche darin bestehen, eine Eigentiimlichkeit des Körpers zn benutzen. Erst dieser Instinkt macht die Eimrichtung niitzlich und damit fähig, im Kampf ums Dasein geziichtet zu werden. Mit Aufwendung vieler Spitzfindigkeit könnte man zwar vielleicht in einzelnen Fällen eine derartige Einrichtung und den Verwendungsinstinkt als unabhängig von einander gezüchtet darstellen, indem man zu dem Prinzip des Funktionswechsels seine \%nflucht nimmt, aber es giebt Beispiele, an denen mit mathematischer Schärfe die Ummöglichlieit einer solchen Ammahme bewiesen werden kann. Das denkbar beste Beispiel ist rielleicht folgendes:

Tedermann weiss, dass im Bienenstaate die Königin das einzige fortpflanzungsfähige Weibchen ist, mon dass dieselbe ihre Zeugungsfähigkeit durch besondere rermüge des Instinkts der Arbeiter iln zu Teil werdende Füitterung erlangt. Hier besteht also der Instinkt nicht etwa in der Benutzung eines am Körper überhaupt sich findenden Gebildes, sondern in der Benutzung einer physiologischen Eigentiimlichkeit, d i e ii ber'haut nur dann eintritt, wenn sie benutzt wirl. Hier hat also die Erscheinung selber ihre Benutzung zur Vor- 
aussetzung, beides kann unmöglich ron einander getrennt werden. Die Selektionstheorie müsste unbedingt annehmen, die Erscheinmo, dass die Art der Nahrung einen solchen Einfluss anf die Organisation ausiibt, sei Hand in Hand gegangen mit dem Instinkt, in der Fütterung der Nachkommen einen Unterschied zu machen.

Dieses Beispiel ist auch deshalb interessant, weil, was nur nebenbei bemerkt sei, an ihm auch die Unrichtigkeit der La marckschen Erklärung des Instinktes durch vererbte Gewohnheit aufs schlagendste nachgewiesen werden kam. Der' Tamarckismus müsste hier die allerabentenerlichsten Voraussetzungen machen, nämlich einmal, dass die Vorfahren der Bienen eine solch raffinierte Schlauheit besassen, diese physiologische Erscheinung zu entdecken, eine Entdeckung, die einem Physiologen von Fach Ehre gemacht haben wïrde, ferner, dass sie iiber die Vorteile der Arbeitsteilung nachgedacht hätten. dass ihnen der Gedanke gekommen sei, auf experimentellem Wege unter Benutzung jener Entdeckung durch künstliche Degeneration der Geschlechtsorgane die Möglichkeit einer strengen Arbeitsteilung herbeizuführen, dass ihnen dieses Ideal einer Sozialpolitik gehngen sei, und dass diese damn zur Gewohnheit gewordene Methode, die soziale Frage zu lösen, sich auf die Nachkommen vererbt habe; humoristisch genug wären diese Voranssetzungen, aber das Allerhumoristischste ist noch dazn der Umstand, dass eben angenommen werden mïsste, nicht von denjenigen Individuen, welche diese Gewohnheit hatten, sonder'n nur von denjenigen, welche sie nicht hatten. sei eben jene Gewohnheit vererbt worden. Denn die Gewohnheit besteht ja darin, sich selbst der Fortpflanzung zu enthalten und andere Individnen besonder's geeignet zur Fortpflanzung zu machen. Es pflanzen sich daher nicht diejenigen Individuen fort, welche diese Gewohnheit haben, sondern nur die, welchen sie zu Gute kommt, nämlich die Königinnen. Auch von der väterlichen Seite konnte die Gewohnheit nicht vererbt werden, dem die Männchen haben sie eben nicht, sie beteiligen sich nicht an der Arbeit Königimnen zu zïchten, ganz abgesehen davon, dass 
die Männchen, die ja keinen Vater haben, die Gewohnheit doch von der Mutter, nämlich der Königin, geerbt haben muissten. Während also der Darwinismus hier an der Komplikation des ron ihm zu fordernden Variierungsinkrementes scheitern wiirde, müsste der Lamarckismus sich sehr bald durch das Harrstrïubende seiner Konsequenzen ad absurdum geführt sehen, und wir haben hier ein Beispiel, das uns in besonders klarer "Veise zeigt, dass weder der eine noch der andere, sondern nur eir dritter noch nicht betretener Weg unserem Ziel uns zuführen kann.

Die angeführten Beispiele für diese zweite Art der Komplikation des Variierungsinkrementes beruhen auf den Beziehungen zwischen den Nervensystem und anderen Oroanen. Solche Reispiele sind vielleicht die deutlichsten, aber durchans nicht die einzigen. Eine einigermassen gründliche Nachforschme wird uns eine Menge derartiger Beziehungen zwischen anleren Teilen des Organismus finden lassen. Betrachten wir z. B. die Entstehung der placentaren Entwicklung und hier wieder speziell die Entstehung der Placenta. Diese wird bekanntich ron Kind und Mutter gemeinschaftlich gebildet. Hier mïssen wir zu einel bestimmten Variierung des Uterus*) immer eine gleichreitige

*) bzw. des miitterlichen Organismns. Diese für de Mutter zn fordernde zweckmässige Variierung hesteht eben in der Fihigheit. anf die Berührung mit dem hefruchteten $\mathrm{Ei}$ in dieser Weise zu reagieren. Dass dies zweckmä-sige Reaktionsweise erst durch das befmehtete Ei anscelöst wird. dïrfw wohl, da cine jungfräuliche placenta materna noch nicht heobachtet wurde, für jedermann ohne weiteres klar scin, und man wird nicht nö́ig haben. mit W. Roux dies erst aus dem Vorkommen der Extranterinsehwangerseluft zu schliessen. Wemn aber Rou $\mathrm{x}$ schon in der Thatsache, dass die zweckmässige Reaktion der Mntter durch die Berührung mit dem befruchteten Fi ausgelüst wird; d. h. in derjenigen Thatsache, die eben das zu erklürende Problem bildet, bereits cinen ,entwickelungsmechanischen Zusammenhang" crblickt, so hat die Entwickelungsmechanik die Aufgabe mit ihrer Lösune rerwechselt. (Vgl. Roux, ..Zicle und Wege der Entwickelungsmechanik" in Merkel-Bonnets "Ergebnissen der Anatomic und Entwickelungsegeschiclite" Band II p. 424, wiederabgedruckt in Rouxs gresammelten Abhandlungen, Band II p. 6S). Roux. welcher ïherhaupt eine präzisc Formulierung seiner 
ganz bestimmte Variierung des Eies postulieren. Die Kompliziertheit des zu fordernden Variierungsinkrementes springt also klar in die Augen. Analoge Fälle sind leicht in Menge anzuführen, doch handelt es sich hiel nicht darum, die Fälle zu erschöpfen. Hier sollten nur sozusagen Paradigmata füı ganze Erscheinungsklassen gegeben werden.

\section{Morphologische Beziehungen zwischen zwei Organismen und das Verhältnis solcher Beziehungen zur Selektionstheorie.}

Die im bisherigen Verlauf unserer Untersuchung angeführten Erscheinungen beziehen sich auf das Verhältnis eines Teils zu einem andern des nämlichen Organismus. Es giebt nun aber auch Beziehungen von Teilen eines Organismus zu Teilen eines andern Organismus, wie die Beziehungen zwischen beiden Geschlechtern, zwischen Insekt und Blüte etc. Hier' muss die Selektionstheorie zu einem Variierungsinkrement des einen Organismus ein genau entsprechendes am andern postulieren. Diese Voraussetzung mag auf den ersten Blick noch komplizierter erscheinen, als in den früheren Fällen, sie ist aber thatsächlich einfacher, und die wenigstens mathematische Möglichkeit, hier mit der Selektionstheorie auszureichen, kann, wemn auch die Unwahrscheinlichkeit ihrer Berechtigung in die Angen springt, doch wenigstens für einige dieser Erscheinungen nicht geradezu gelengnet werden. Es soll dies hier ausführlich dargelegt werden: nicht um für die Selektionstheorie zu werben, sondern um durch thunlichst scharfe Darlegung des Unterschiedes dieser Fälle von den frühern die Grenzen des

Ansichten nicht selten vermissen lässt, hat sich ïbrigens an dieser Stelle so unbestimmt ausgedrückt, dass man ihm geradezu die Auffassung imputieren künnte, der Uterus bzw. der mütterliche Organismus sei für den Akt des Lebendiggebärens gar nicht angepasst, sondern nur das Ei habe im Laufe der Generationen gelernt, diejenigen speziellen Reize herauszufinden, welche bei der Mutter die entsprechenden zweckmässigen Veränderungen als pathologische Reaktionen erzwingen. Beror aber Roux nicht in bestimnten Worten diese Auffassung als die seinige bezeichnet hat, bedarf dieselbe wohl keiner Diskussion. 
Machtbezirkes der Selektionstheorie möglichst genau zu bestimmen und dadurch noch einmal aufs evidenteste zu zeigen, dass die früher angegebenen Fälle völlig ausserhalb dieses Nachtbezirkes liegen.

Man kann nämlich der Selektionstheorie nichts 'l'riftiges einwenden, wenn sie behauptet, dass sie ja lier iiber den Grad der Kompliziertheit und Regelmässigkeit des einzelnen Tariierungsinkrementes durchaus keine Voraussetzung zu machen brauche, sondern diesen beliebig annelımen diurfe.

Betrachten wir z. B. bei diöcischen Pflanzen die gegenseitige Anpassung der Bliiten beider Geschlechter. Auf der' einen Pflanze entwickeln sich nur männliche, auf der andern Pflanze dagegen nur weibliche Bliiten. I)iese miissen beide eine ganz bestimmte Beziehmng zu einander haben, und hier haben wir, wenn wir uns die Entstehung auf selektionstheuretischer Grundlage denken, allerdings zu einer bestimmten Variierung im einen Geschlecht eine genau entsprechende im andern Geschlecht zu postulieren. Somit kömnte es wohl auf den ersten Blick den Anschein haben, als kämen wir hier nicht einfach mit der Amnalıme einer regellos nach allen Richtungen erfolgenden Variierung aus, als müsste auch hier das zu fordernde Tariierungsinkrement eine bestimmte Bedingung befriedigen. Bei näherem Zusehen erkemen wir jedoch, dass die: nicht der Fall ist, weil nämlich die zwei Variierungserscheinungen, die sich entsprechen müssen, nicht für einen und denselben Organismus zu fordern sind. Die Selektionstheorie kamn hier allerdings sagen: unter tausenden nach allen Richtungen hin variierenden Individuen des einen Geschlechts wird sich immer wieder ab und zu eine Variierung gefunden haben, die zufällig zu einer bestimmten Variierung der entsprechenden Gebilde im andern Geschlecht gepasst hat. Hier braucht also die Kombination des zu einander Passenden und damit die zweckmässige Kompliziertheit nicht schon für das einzelne Variierungsinkrement gefordert zu werden. Was zu einander passt, ist nicht schon von vornherein beisammen, sondern es wird erst durch die äussern Umstände zusammengebracht. Allerdings muss hier 
dem Zufall eine noch grössere Rolle zuerteilt werden, als er sie soust in der Selektionstheorie ohmehin spielt, denn er muss ja das jeweilig für einander Passende zusammenführen oder wenigstens in direkte Beziehung bringen. Der Zufall, häufig als der wunde Punkt der Selektionstheorie bezeichnet, ist hier geradezu ihr Rettungsanker. Denn sobald wir die Erreichung der direkten Beziehung beider Geschlechter nicht, weuigstens primär, vom Zufall abhängen lassen, sondern von Eigenschaften, die einem derselben oder beiden zukommen, dann komplizieren wir das Variierungsinkrement, indem wir zu der ersten Eigentiimlichkeit noch eine andere das Zusammentreffen beider Geschlechter begïnstigende Eigentümlichkeit fordern müssen. So lange aber dieses Zusammentreffen nur vom Zufall abhängt, so lange bleibt hier die selektionstheoretische Erklärung wenigstens mathematisch möglich. In den wenigsten Fällen wird dies num allerdings zutreffen, und wir haben oben schon einen Fall berührt, wo eine solche Erklärung absolut ausgeschlossen erscheint: kein Mensch wird annehmen, dass zufällig einmal ein Penis (sozusagen aus Versehen) in eine zufällig passende Vagina hineingeraten sei. Hier muss unbedingt zu jener Variierung, welche die Bildung der Begattungsapparate herbeifuhrt, auch die entsprechende Variierung des Instinktes treten, welche eben die Begattung herbeifuihrt, d. h. welche erst jene andere Tariierung nïtzlich und fähig macht, im Kampf ums Dasein geziichtet zu werden.

\section{Zusammenfassung der bisherigen Resultate.}

Aus den bisherigen Betrachtungen ersehen wir, dass Gebildeu, welche durch die Selektionstheorie erklärt werden sollen, mindestens zwei Merkmale zukommen müssen. Ein solches Gebilde darf nämlich zunächst nur einmal an einem Organismus sich finden, ferner aber darf es zu keinem andern Teil desselben Organismus in einer notwendigen Beziehung stehen, d. h. in einer Beziehung, die man sich auch nicht als in frïherer Zeit fehlend denken, die man also nicht etwa als eine später erworbene auffassen kann. Sehen wir uns aber um im 
Reiche der Organismen, so dürfte es uns schwer fallen, Bildungen zu finden, welche diese beiden Bedingungen befriedigen. Von der letzten Bedingung kann dies vielleicht nicht von vornherein in dieser Allgemeinlleit gesagt werden: hier dürfte es wohl jedesmal auf den einzelnen Fall ankommen; aber bezüglich der ersten Bedingung behaupte ich, dass es wohl kaum ein Gebilde giebt, welches dieselbe erfiillt. Schon die Symmetrie, welche fast alle Organismen beherrscht, macht Organe, die in der Einzahl vorhanden sind, zur Ausnahme; und selbst solche, wie Milz etc., bestehen doch wieder aus T'eilgebilden, die unter einander homodynam sind.

Wenn wir zwei gleiche Gebilde in verschiedenen 'Tierklassen finden, so suchen wir nach einem kausalen Zusammenhang und finden denselben in der gemeinsamen Abstammung. Es ist widersinnig, für die Entstelmng homologer (iebilde einen Kausalzusammenhang zu suchen, die Entstelung homodynamer Gebilde dagegen als rein zufällig sich vorzustellen.

\section{Die Erscheinungen der Rückbildung und ihr Verhältnis zur Selektionstheorie.}

Wir verlassen damit diese Gruppe von Jinwinden, welche sich anf die Kompliziertheit des zu fordernden Variierungsinkrementes gründen und wenden uns zu einer andern Klasse ron Erscheinungen, welche nicht sowoln ans den bisher verfolgten Gründen, als insbesondere deshalb der Erklïrung durch die Selektionstheorie widerstreben, weil jene Erscheinungen unter der Herrschaft des Selektionsprinzipes in ganz anderer Weise hätten zu Tage treten müssen, als es in Wirklichkeit der Fall ist. Es sind dies die Erscheinungen der Rückbildungen.

Dass zur Erklär'ung der Rückbildungen die Selektionstheorie nicht genügt, scheint Darwin selbst eingesehen zu laben; denn zur Dentung dieser Vorgänge nimmt er nur in einzelnen Fällen seine Theorie in Anspruch (z. B. bei den Augen des Maulwurfs), in den meisten Fällen adoptiert er hier die Lamarcksche Erklärung. Nenerdings ist von derjenigen Seite, 
welche dem Selektionsprinzip die Alleinherrschaft zu sichern am eifrigsten bestrebt ist, eine Erklärung der Rückbildungserscheinungen auf selektionstheoretischer Grundlage versucht worden.

Weismann sieht die Veranlassung der Rückbildung in der "Kehrseite der Naturzüchtung“, der "Panmixie“, einem Prinzip, dessen Vorhandensein nicht nur von Anhängern, sondern sogar von Gegnern der Weismannschen Anschaumgen zugegeben wird. Die folgende Betrachtung dürfte aber vielleicht zeigen, dass die Theorie von der Panmixie eine nicht. ganz unanfechtbare Rechmung ist.

Weismann sagt: „wenn wirklich die Zweckmässigkeit der lebenden Wesen in allen ihren Teilen auf dem Vorgange der Naturziichtung beruht, dann muss diese Zweckmässigkeit auch durch dasselbe Mittel erhalten werden, durch welches sie zu stande gekommen ist, und sie muss wieder verloren gehen, sobald dieses Mittel, die Naturziichtung in Wegfall kommt". Es soll also nach Weismann, wenn z. B. Tiere sich gewöhnt haben, in dunkeln Höhlen zu leben, das Auge sich deshalb zurückbilden, weil es für das Tier nun einerlei ist, ob es ein Auge besitzt oder nicht, und mithin die natürliche Zuchtwahl nicht mehr auf das Auge wirkt. Es haben nun nicht mehr diejenigen Nachkommen, welche die besten Augen haben, die grösste Chance, im Kampf ums Dasein übrig zu bleiben, sondern das schlechtere und das bessere haben die gleiche Wahrscheinlichkeit, zu überdauern: es mengen sich die schlechten mit den guten, "und das Resultat davon kann nur eine allgemeine Verschlechterung der Augen sein".

Machen wir uns die Wirkung der Selektion eimmal in möglichst präziser Form klar. Wir betrachten ein Tier, in dessen Interesse es liegt, ein möglichst gutes Auge zu besitzen. Es sei uns eine Generation gegeben, die ein Auge besitzt von einem gewissen Ansbildungsgrad, einer Grösse, welche mit der Zahl $\mathrm{x}$ bezeichnet werde. Infolge der Variierung ist bei den Nachkommen das Auge verschieden, bei dem einen besser, bei dem andern schlechter. Die Zahl der Nachkommen betrage 
$=2 \mathrm{n}$. Ein Nachkomme habe ein um etwas besseres Auge als der Erzenger; das Auge hat also den Organisationsgrarl $=\mathrm{x}+\mathrm{dx}$, wobei $\mathrm{dx}$ beliebig klein angenommen werden darf. Ein anderer Nachkomme habe ein noch etwas besseres Ange $(\mathrm{x}+2 \mathrm{dx})$, ein dritter ein noch etwas besseres $=\mathrm{x}+3 \mathrm{dx}$ л. s. w., ein $\mathrm{nter}=\mathrm{x}+\mathrm{ndx}$. Aber mit der gleichen Wahrscheinlichkeit muss ich zu jedem Individum mit besserem Auge auch ein solches mit einem um ebensoviel schlechtern Auge annehmen. Zu dem Auge $=\mathrm{x}+\mathrm{dx}$ tritt ein solches $=\mathrm{x}-\mathrm{dx}$. zu dem Auge $=x+2 \mathrm{dx}$ ein solches $=\mathrm{x}-2 \mathrm{dx}$ u. s. w. zu dem Ange $=x+n d x$ tritt ein solches $=x-n d x$. Wollte ich dies nicht annehmen, so wïrde ich ja eine 'T'endenz zur Vervollkommnung voraussetzen, was ja gerade Darwin und Weismann vermeiden wollen. Wir erhalten also folgenden Stammbaum:

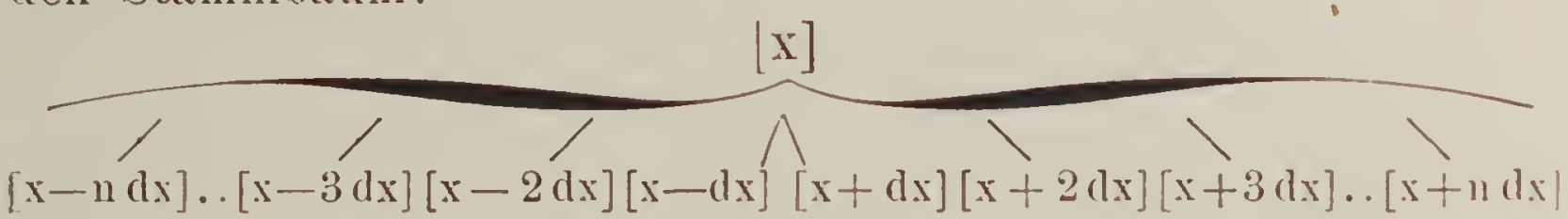

Das heisst: von dem Auge mit dem Ausbildungsgrade $x$ stammen 2 n Augen ab, die unter einander nicht ganz gleich sind. Da aber gleich viel Wahrscheinlichkeit vorhanden ist, dass das Auge der Nachkommen besser ist, als dass es schlechter ist, so kommt zu jedem bessern Ange ein um ebensoriel schlechteres, dergestalt, dass sich die Augen der 2 n Nachkommen ihrem Organisationsorad nach, wie dies in obigem Schema geschehen ist, symmetrisch um das Auge des Erzeuger: anordnen lassen. Da die Grösse $d x$ ein Differential ist, $d . h$. kleiner als jede beliebig klein angegebene Grösse angenommen werden darf, so kann der Unterschied zwischen dem besten und dem schlechtesten Ange (= $2 \mathrm{ndx}$ ) noch ein ganz minimaler sein. Von diesen 2 n Nachkommen kömmen sich num nicht alle erhalten. Da ein gutes Auge vorteillaft ist, so haben jene mit den schlechtesten Augen die grösste Wahrscheinlichkeit, zu Grunde zn gehen. Nehmen wir an, es müsste ron den 2 n Individuen nur eines mutergehen, z. B. das mit der grö̈ssten Wolff, Beitrige zur Kritik der lorwiuschen Jehre. 
Wahrscheinlichkeit, also dasjenige mit dem Auge $=\mathrm{x}-\mathrm{ndx}$, so ist der Durchschnittswert der Augen der Nachkommen, welcher vorher $=\mathrm{x}$ war, jetzt $=\frac{(2 \mathrm{n}-1) \mathrm{x}+\mathrm{ndx}}{2 \mathrm{n}-1}=\mathrm{x}+$ $\frac{n d x}{2 n-1}$, und dies wird der Durchschnittswert der Augen sein, die bei regelloser Kreuzung der Ueberlebenden resultieren, so dass ein minimaler Fortschritt (bezeichnet durch die Grösse $\frac{\mathrm{ndx}}{2 \mathrm{n}-1}$ zu konstatieren ist. Der Durchschnittswert der Augen der ersten Nachzucht ist also $=x+\frac{n d x}{2 n-1}$. Da aber nicht alle sich fortpflanzen können, sondern wieder die schlechteren ausgemerzt werden, so ist der Durchschnitswert derjenigen Lndividuen, die sich fortpflanzen, grösser als $\mathrm{x}+\frac{\mathrm{ndx}}{2 \mathrm{n}-1}$, und bei fortgesetzter Wiederholung dieses Prozesses kamn der Fortschritt immer deutlicher werden.

Nehmen wir nun an, dass die Selektion wegfalle, d. h: dass jeder Nachkomme gleichviel Wahrscheinlichkeit hat, erhalten zu bleiben und sich fortzupflanzen, so ist natürlich der Durchschnittswert derjenigen Individuen, welche sich fortpflanzen, in Bezug auf das fragliche Organ kein anderer als der Durchschnittswert derjenigen, die geboren werden, welcher gleich ist dem entsprechenden Wert des Erzeugers. Denn wenn ich auf der linken Seite einen Nachkommen streiche, so muss ich mit derselben Wahrscheinlichkeit auch den entsprechenden anf der rechten Seite streichen. Dadurch wird aber eine Aenderung des Durchschnittswertes unmöglich, der Schwankungsmittelpunkt, wie man sich anch ansgedrïckt hat, wird nicht verschoben, als Durchschnitt erhalten wir die Grösse x. Das Auge müsste also nach Wegfall der Selektion genau auf demjenigen Ausbildungsgrade beharren, den es gerade hat. "Gut" und "Schlecht:" sind sich eben völlig gleichwertig. Dass das Auge besser wird, ist daher ebenso wahrscheinlich, als dass es schlechter rird, 
deshalb ist das Wahrscheinlichste, dass es bleiben wird, wie es ist.

Unter solchen Umständen kam aber, wemn de: Lamarckismus nicht zu Hilfe gelufen wird (und dass dies mzulässig ist, hat Weismann, wie rïckhaltlos merkannt Werden muss, auf das iiberzeugendste dargethan, indem er auf die Rückbildung solcher Gebilde hinwies, deren Benutzung nu eine passive ist), die Selektionstheorie die Rückbildmngerscheinmoen allgemein nu' so denten, wie Darwin die Rückbildung der Maulwurfaugen erklärt, indem nämlich im schwmole des betreffenden Organs ein Vorteil gesucht wird, der eben die Ziichtmo der Individuen mit riickgebildeten Organen verursacht. Aus welchen Gründen sich Darwin hiergegen gesträubt hat, ist schwer ersichtlich: viel gezwungener als in den meisten andern Fälen wäre die Erklärung nicht geworden, dem irgend ein Vorteil liesse sich ja wohl immer herausklanben. Dass aber jede selektionstheoretische Erklärung durchans falsch wäre, wird insbesondere klar bei richtiger Würdligung des Umstandes, dass bei Rückbildungen das ,.biogenetische Grundgesetz" in der Weise zur Geltung kommt, dass riickgebildete Organe im Embryonal- oder Jugendleben sich noch anlegen und el'st damn wieder zurïckbilden, so dass anch hierin die ontogenetische Entwicklmng die phylogenetische wiederholt.

Eine durch gehänfte Variiermugen bedingte Riickbildung muss man siclı am einfachsten doch wohl so rorstellen, dass das betreffende Organ bei einigen Individuen etwas schwächer auftrat, bei den zur Fortpflanzmng gelangenden noch schwächer u. s. w., bis schliesslich eine Generation resultierte, bei der' ras betreffende Organ finst gar nicht mehr zum Vorschein kam. Aber die Existenz des biogenetischen Grundgesetzes wiirde den Selektionstheoretiker zwingen, auzmehmen, dass nicht dies der Vorgang gewesen; das Postulat, das an die Tariierung gestellt werden muisste, wäre nicht einfach eine immer schwächer werdende Entwicklung: es miisste für jede Generation eine durch Variierung berlingte minimale $R$ iickbildung angenommen werden. Man kann num ja der Variierung vieles zumuten: das 
ist ja das Bequeme der Selektionstheorie; man kann speziell hier dem Selektionstheoretiker die Möglichkeit nicht bestreiten, dass es durch rein zufällige Variierung manchmal vorgekommen sein mag, dass ein Organ sich bildete und im Lauf des individuellen Lebens sich wieder zuriickbildete. Aber man kann dagegen sagen: viel häufiger ist jedenfalls der Fall vorgekommen, dass die Variierung nicht auf jenem indirekten Wege der Rückbildung das Resultat des schwächern Ausbildungsgrades erreichte, sondern auf dem ganz direkten Wege der geringeru Fntwicklung. Solche Variierungen, wo Organe einfach sich etwas schwächer anlegen, beobachten wir ja tagtäglich. Also müssten, wenn die Verhältnisse zur Rückbildung eines Organes drängen, weit mehr solcher Individuen zur Auswahl gelangen, bei denen das Organ von rornherein schwächer angelegt war, als solche, bei denen das Organ sich etwas rïckgebildet hatte. Auf diese Art wäre aber die Erscheinung des biogenetischen Grundgesetzes nie und nimmer zu stande gekommen. Hier haben wir also einen Fall, wo wir in der Lage sind, die Geschichte der phylogenetischen Entwicklung sozusagen direkt zu verfolgen und sie mit derjenigen zu vergleichen, welche die Selektionstheorie voraussetzen mïsste. Und die Erscheinung, welche die Selektionstheoretiker in seltsamem Widerspruch mit ihrer Zufallstheorie das biogenetische Grund-,Gesetz" nannten, beweist, dass es sich hier allerdings um ein wirkliches Gesetz der Entwicklung handelt.

Der Fall ist auch deshalb interessant, weil er zeigt, dass hier die Selektion gar nicht, aucl nicht etwa nebensächlich im Spiel war. Demn man kamn hier auch nicht einmal, wie rielleicht in andern Fällen sagen: die Selektion ist nur nicht das Primäre, aber sie spielt eine sekundäre Rolle und wällt aus den zweckmässigen Aenderungen, die aus andern Grïnden erfolgt sind, nun noch nachträglich die allerbesten heraus. Denn hier ist der Vorgang demjenigen Prozess gerade entgegengesetzt, der nach der Selektionstheorie eintreten muisste: die Selektion, wemn sie Einfluss iibte, komnte daher nicht eimmal als Korrektir, sondern im Gegenteil höchstens hemmend wirken. 


\section{Sekundäre Sexualcharaktere und andere korrelative Bildungen.}

An diese Fälle reiht sich vielleicht am besten die Betrachtung der Folgen, welche frïlıeitige Sterilität anf die Ansbildung von sekmudären Geschlechtscharakteren ansiibt. Wir kömmen ja diese Erscheinmngen anch in gewissem simne zu den Rückbildungen rechnen; sie haben aber insbesondere anch das mit den vorigen Fällen gemeinsam, dass wir hier ebenfalls einen im individuellen Leben des Organismus sich abspielenden Vorgang beobachten kömnen, der nach der Selektionstheorie nicht eintreten durfte.

Nach der Selektionstheorie entstehen ja sekmndäre (ieschlechtsmerkmale dadurch, dass eben Individuen des einen Geschlechts, bei welchen durch zufällige Variiermug eine Andentung solch eines Merkmals dil war, mehr Chancen hatten, sich fortzupflanzen and diese Eigentïmlichkeit auf die Nachkommen ihres Geschlechts zu vererben, von denen damm durch den gleichen Prozess immer diejenigen zur Fortpflanzmng ansgewählt wurden, welche die betreftende Eigentïmlichkeit an stärksten besassen. Es soll also zwischen jenen Gebilden und dem Geschäfte der Zeugung an und für sich nicht, der geringste Zusammenhang existieren. Dann ist aber schwer erklärlich, warım jene sekundären Geschlechtsmerkmale sich häufig nul' zur' Zeit der' Geschlechtsthätigkeit bilden mnd nachher wieder' verschwinden, wie \%. B. der Hochzeitskamm der T'ritonen. Aber geben wir einmal zu, das sei bloss ein zufälliges \%usammentreffen, indem eben diejenigen zur F'ortpflanzmng gelangten, welche gerade zufällig um die "Zeit der Brunst eine bald wiedel' zufällig verschwindende Verstärkung des Kammes besassen. Es ist zwar mmöglich, sich dies, insbesondere das Verschwinden hes Kammes, vor'zustellen, weil ja, wenn anch das spätere Terschwinden des Kammes dem Tiere irgend einen Vorteil gebracht haben sollte, dieser bei der Selektion in keiner Weise sich geltend machen komnte, oder doch nur in Bezug anf das Individum aber nicht auf dessen Nachkommen, aber nehmen wir eimmal an, das sei alles in Ordnung: wie erkiärt sich dann, 
dass z. B. beim kastrierten Hirsch kein Geweih sich entwickelt, dass der kastrierte Nensch hohe Stimme behält, keinen Bart bekommit u. S. W., u. s. W.?

Auch andere Rückbildungen, welche nach Aufhören der Geschlechtsthätigkeit normal sich einstellen (z. B. Anfhören der Flimmerbewegung im Uter'us des Weibes nach Aufhören der Menstruation, Verlust der Fliigel nach der Begattung bei Insekten*) etc.) bieten der Selektion die grö̈ssten Schwierigkeiten, denn wenn hier die Riickbildung einen Vorteil böte, welcher die Auswahl der Individuen, bei welchen diese Rückbildung auftrat, herbeiführte, so könnte dieser Selektionsprozess doch erst nach der Fortpflanzungszeit eintreten, auf die nachfolgenden Geschlechter daher von keinem Einflusse mehr sein.

Der unbestreitbare Zusammenhang, welcher zwischen der' Geschlechtsthätigkeit und den sekmuären Geschlechtsmerkmalen besteht, ist nun aber nicht etwa durch das Wort "Korrelation" erklärt. Es ist natiirlich richtig; dass eine Änderung irgend eine andere im Gefolge haben kann, dass es also korrelative Abänderungen giebt, aber ist denn damit vielleicht erklärt, dass eine bestimmte zweckmässige Abänderung nun auch eine andere für den jeweilig vorliegenden ganz speziellen Fall nuitzliche Abänderung bedingt? Korrelative Abänderungen beziehen sich ja in den meisten Fällen, wo wir ron solchen sprechen, auf ganz bestimmte Verhältnisse der Aussenwelt. Sich zur Erklärung solcher Erscheinungen mit der Konstatierung eines Gesetzes der Korrelation zufrieden geben, heisst einfach eine praestabilierte Harmonie zwischen der Entwicklung der Organismen und den Verhältnissen der Aussenwelt amnehmen. Das Rätsellafte ist ja zunächst nicht der Umstand, dass es ïber'haupt Korrelationserscheinmogen giebt (wenngleich wir natürlich auch hierfür ebensowenig, wie für irgend eine andere Tuebenserscheinung eine Erklärung haben). sondern der Lmstand, dass eine Eigentimmlichlieit eine andere korrelativ im Gefolge

*) In diesem letzteren Fall ist vielleicht doch ein Vorteil fuir die Art durch Termittlung der Brutphlege denkbar. 
hat, die eben gerade für besondere änssere \%wecke rorteilhaft ist. Hier kann die Selektionstheorie nichts ausrichten, demn der Selektionsprozess hat doch keinen Einfluss auf die Variierungsgesetze, zu welchen die Korrelationsgesetze gehören; diese müssen vielmehr rorausgesetzt werden.

Es giebt ibrigens 'T'hatsachen, die mir darauf hinzudenten scheinen, dass die kolrelativen Beziehungen noch viel rerwickelter sind, und dass korrelative Beziehnngen gar nicht immer auf die Entstehung korrelativer Abänderungen zurïckzuführen sind, sondern dass, was ja noch riel rätselhaftel ist, eine Korrelation erst sekundiar erworhen werden kann, wie folgendes Beispiel zeigen diurfte.

Von den drei rerschiedenen Individuen des Bienenstantes hat nur die Arbeitsbiene an der Innenfliche des 'Tarsus regelmässige Borstenreihen, sogenamnte Bürstchen. Da die Arbeitsteilung immer eine höhere Differenzierung ist, so kann en keinem Zweifel muterliegen, dass ursprünglich bei allen Formen die Beine gleich waren. Kaum zn entscheiden diurfte wohl die Frage sein, ob ursprünglich sich die Bürstchen sowohl bei männlichen als auch bei weiblichen Tndividuen difterenzierten. sodass das Fehlen derselben bei den Drohnen als Riickbildung betrachtet werden müsste, oder ob die Bürstchen grleich rom rornherein als sekundäres Geschlechtsmerkmal der Weibchen auftraten. Im erstern Fall wïre also die Bildung primair in keinerlei Korrelation zum Geschlechtsapparate gestanden, diese müsste vielmeln erst später erworben worden sein. Im zweiten Fall wären die Büistchen als zum Geschlechtsapparate kol'relative Bildungen entstanden, aber in beiden tiallen muste eine Änderung des Korrelationsverlü̈ltnisses eing etreten sein, die Korrelation musste nämlich eine reziproke werden: die Entstehmo ron Bürstchen ist zwar an das weibliche Geschlecht gekniipft, jedoch in der Weise, dass die Bürstchen nur anftreten, wem die Geschlechtsorgane nicht zur Ausbildung kommen. 


\section{Die geschlechtliche Zuchtwahl.}

Im vorigen Kapitel haben wir eine Reihe von Erscheinungeir betrachtet, zu deren Erklärung Darwin nicht die ursprüngliche natürliche, sondern die ,geschlechtliche Zuchtwahl“ anwendet. Dieser Modifikation der Zuchtwahllehre ist es bekamntlich nicht gelungen, sich eine eben so starke Anhängerschaft zu erobern, und selbst von Anhängern der natürlichen Selektion, ja sogar von Wallace, der die Lehre von der natïrlichen Zuchtwahl, unabhängig von Darwin, ebenfalls aufgestellt hat, sind gegen die sexuelle Zuchtwahl so gewichtige Bedenken erhoben worden, dass sie sich auch bei den überzengtesten Anlängern Darwins keiner sehr grossen Beliebtheit erfreut. Nan hat sich allerdings hierbei nicht genügend klar gemacht, dass Darwin ganz Recht hatte, wenn er die geschlechtliche Zuchtwahl als eine notwendige Ergänzung zur natïrlichen betrachtete. Denn da es eben selbst dem gewandtesten Interpreten schlechterdings unmöglich ist, den sexuellen Zierden ${ }^{1}$ ) irgend eine Bedentung für das individuelle Leben des Besitzers unterzuschieben, so ist damit auch jede Möglichkeit abgeschnitten, den Kampf ums Dasein zu verwerten. Darf also der Kampf um die Fortpflanzung nicht zu Hilfe gerufen werden, so zeigt die Selektionstheorie hier eine so klaffende Lücke, dass es schwer begreiflich erscheint, wie man zugleich die natürliche Zuchtwahl annehmen, die geschlechtliche aber ablehnen kamn.

Übrigens scheinen mir in der Kritik der geschlechtlichen Zuchtwahl noch nisht alle wesentlichen Momente beriicksichtigt zu sein, insbesondere auf einen Punkt möchte ich daher bei dieser Gelegenheit die Aufmerksamkeit lenken.

Betrachten wir einmal das Verhältnis der geschlechtlichen zur natïrlichen Zuchtwahl. Wie allbekannt, ist die natürliche Selektion eine Folgerung aus dem Maltusschen Satze, dass

1) Ausschliesslich von diesen sekundären Geschlechtsmerkmalen, welche dem Individuum zum Schmucke dienen, nicht von dencn, welche cine Wafte zur Vertreibung anderer Männchen bilden, ist im folgenden die Rede. 
die Vermelnung der Oroanismen rascher erfolgt als es den' Existenzbedingungen entspricht, dass infolge dessen weit mehn Organismen zur' Welt kommen, als auf der Welt bleiben kïmen, ๙. l. dass vielen, an und für sich lebensfähigen Individuen einfach die Gelegenheit znm Leben fehlt. Diese Voranssetzung ron der 'Tlheorie der natïllichen Zuchtwahl ist eine unbestreitbare Thatsache. Die entsprechende Toranssetzung für die 'Theorie von der geschlechtlichen Zuchtwahl ist die, dass von allen fortpflanzungsfähigen Organismen nur eine beschränkte Zahl Gelegenheit hat, sich fortzupflanzen. Diese Voraussetzung ist keineswegs so selbstverständlich, und Darwin macht demn auch grosse Anstrengungen, um es plausibel erscheinen zu lassen, dass einer Anzahl oder eigentlich der Melnzahl ron Mitgliedern des einen Geschlechts. z. B. des mämnlichen, die Gelegenlleit zur Begattung fehlt oder wenigstens seltener greboten wird. Bei Monogamie und Gleichheit der Individuenzahl in beiden Geschlechtern ist dies zunächst nicht denkbar; weil, anch wemn die schönsten sich gegenseitig gepaart haben, dadurch den anderen die Gelegenheit zur Begattung nicht geschmälert ist. Nur wem einer grösseren Załlıl männlicher Individuen eine weibliche Minorität gegenuiber'steht, ist es denkbar, dass eine Anzahl Männchen zu kul\% kommt. Ein solches Verlältnis der Individnenzahl hat Darwin anch thatsächlich eine Zeit lang fïl die mit sekundïren Geschlechtscharakteren geschmiickten Spezies angenommen ${ }^{1}$ ). Nachrlem er sich jedoch von der Irrigkeit dieser Amnahme ïberzengt latte, suchte er das mumerische Überwiegen der Nïnnchen auf andere Weise walırscheinlich zu machen. Am einfachsten ist dies natiirlich für die Fälle von Polygamie, da lier auch bei Gleichheit der Individnenzahl in beiden Geschlechter'n eine lelative Überzahl der Männchen vorhanden ist. Wie aber Dar'win selbst anerkennt ${ }^{2}$ ), bieten viele streng monogamen

1) Abstammug des Menschen, deutsch ron Carus, 18 1, Band I p. 230 .

2) 1. c. Band I p. $235 \%$. 
Thiere scharf ausgesprochene sekundäre Geschlechtsmerkmale dar. Deshalb sucht Darwin eine relative Über'zahl der Männchen auf folgende Art abzuleiten. Da die Tiere variieren, so wird die Zeit der Geschlechtsreife nicht bei allen Weibchen genau die gleiche sein, sondern bei dem einen etwas früher, bei dem andern etwas später eintreten. Diejenigen Weibchen, bei welchen die Geschlechtsreife am frühesten eintritt, sind die kräftigsten und gesïndesten, was wir Darwin einmal glauben wollen. Diese beschränkte Zahl der geschlechtsreifen Weibchen kann sich nun von den jetzt wirklich in der Überzahl rorhandenen Männchen diejenigen heraussuchen, die ihnen am besten gefallen, und da diese Weibchen die gesündesten und kräftigsten sind, so werden die Nachkommen vom Vater den betreffencien Schmuck, von der Mutter Kraft und Gesundheit erben und aus letzterem Grunde iiberhaut im Kampf ums Dasein im Vorteil sein, sodass damit der geschlechtliche Schmuck auch durch die natürliche Selektion gez ïchtet wird. Der naheliegende Einwand, dass aus der Variierung auch die ungleichzeitige Geschlechtsreife del Männchen gefolgert werden muss, wird im voraus pariert durch die Tersicherung; dass die männlichen Individuen überhaupt früher geschlechitsreif werden oder jedenfalls frïher auf der Wahlstatt erscheinen als die weiblichen, sodass schon viele leistungsfähige Männchen auf das erste Weibchen warten.

Es ist klar, dass wir mit den bis jetzt gewonnenen Hilfstruppen höchstens vielleicht in den Stand gesetzt sind, die sekundären Geschlechtscharaktere del Mäunchen zu erklären. Nun finden sich ja allerdings solche Charaktere am häufigsten und ausgesprochensten im männlichen Geschlecht. Abel auch das weibliche Geschlecht steht nach Darwin unter dem Einfluss der geschlechtlichen Zuchtwahl, und beim Menschen z. P. mïssen die geschlechtlichen Zierden beider Geschlechter auf diesem Wege erklärt werden. Denn nicht nur der männliche Bart. sondern anch die mannigfachen Reize. welche dem andern Geschlechte den Beinamen des ,.schönen" erobert haben, müssen nach Darwin durch sexuelle Zuchtwahl entstanden gedacht 
werden. Zur Erklärung der männlichen Zierden müsste also ein numerisches Überwiegen auf der männlichen, zur Erkiärung der weiblichen Schönheit ein Überwiegen auf der weiblichen Seite angenommen werden.

Darwin scheint diese Schwierigkeit wohl gefühlt zu hahenl. er hat sie aber nicht offen ausgesprochen, sondern el hat gesucht, sie zu umgehen, indem er mit einer raschen, fast unmerklichen Wendung die mit grösseren Reizen ansgestatteten Individuen anch die kräftigsten sein lüsst ${ }^{1}$ ). Sind diejenigen Individuen, welche eine sexuelle rierde an ansgesprochensten besitzen. zugleich die kräittigsten. und paren sich diese immer mit einander, so werden die Nachkommen dieser Paare von dem gleichgeschlechtlichen Elter den jeweiligen Schmuck, ron beiden Eltern aber Kraft und Gesmolheit erben und im Kampf mms Dasein den Nachkommen der andern Paare ïberlecen sein. so dass also die Zierden beider Geschlechter numeh" dur h die natïrliche Selektion geziichtet werlen.

Diese Verschmelzung von Schönheit und Kraft, die Danwin

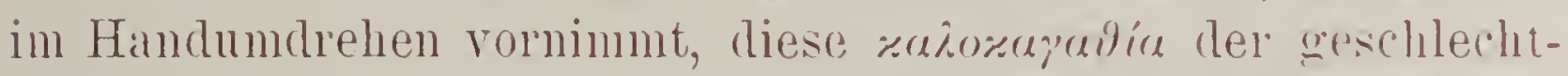
lichen /uchtwahl, diuf aber nicht einfach eingeschmuggelt. sondern sie muss begrindet werden, und diese Begrimdun diurlte für eine grosse Reilıe von Fïllen nicht ganz leicht sein.

Es ist wahr, dass muter Lmstïnden ein gut entwickeltes sekmuäres Geschlechtsmerkmal iuberhant von einem k!aftigen Individumm zengt, dass \%. B. nicht selten von einem stark entwickelten Bart auf einen kiättigen Mann geschlossen werden darf. Aber hierbei ergeben sich doch so viele Ansnalmen, dass es zunächst sehr zweifelhaft ist, ob wir diese nul als Bestätigung einer Regel auffassen dürfen. Fs ist dabei inshesondere zu berïcksichtigen, dass nicht immer der Besit\%, sondern unter Unständen anch die Abwesenheit eines solchen Merkmals als Reiz wirkt. Gerade der Bart ist hier ein lehrreiches Beispiel. Die Bartlosigkeit der F'rau, die Unterdriickung der doch zweifellos im weiblichen Geschlecht nachweisbaren

l. c. Band I p. $231,232,239$. 
Tendenz zum Bartwuchs, müsste ja ebenfalls durch sexuelle Zuchtwahl erklärt werden. Dazu kommt, dass der Bart durchaus nicht bei allen Stämmen geschätzt, dass vielmehr bei manchen Völkern im Gegenteil eine Züchtung der Bartlosigkeit angenommen werden müsste. Die bartlosen Neuseeländer haben sogar ein Sprichwort: „dass es für einen harigen Mann keine Frau giebt" ${ }^{1}$ ). Hiel müssten also die ausgewählten Bartlosen die Kräftigsten gewesen sein.

Die Schwierigkeit liegt eben darin, dass Kraft und Gesundheit eine objektive, Schönheit aber nur eine subjektive Realität besitzt. Wie Darwin selbst ausführlich erörtert, sind die Begriffe von Schönheit im höchsten Grade schwankend. Wemn z. B. bei den Männeln eines Stammes die Franen mit platter Nase, bei den Männern eines andern Stammes die Weiber mit schärferem Gesichtsrorsprung für schöner gelten, sollen dann diejenigen Individuen, welche die jeweilig bevorzugte Eigentïmlichkeit besitzen, in beiden Fällen vielleicht auch die gesündesten sein? Oder soll ein Hottentottenweib mit so mächtig entwickeltem Hinterteil, dass dessen Schwere sie am Aufstehen hindert ${ }^{2}$ ), bloss deswegen auch die Kräftigste ihres Stammes sein, weil das Herz der feinfühlenden Somali-Männer von solchen "Reizen" besonders gerührt wird? Die extensive Ausdehmung eines und desselben Merkmals kamn nach beiden Extremen hin für das andere Geschlecht zum Gegenstand der Anziehung werden, und nur vom zufälligen Geschmack des andern Geschlechts hängt es ab, ob das eine oder das andere bevorzugt wird. Gerade weil nach der Darwinistischen Naturerklärung solche Charaktere nicht die geringste Beziehung zu irgend einer Funktion des Besitzers haben, darf am allerwenigsten von diesem Standpunkt aus eine Korrelation zwischen lem betreffenden Merkmal und einer bestimmten Körperkonstitution vorausgesetzt werden.

1) 1. c. Band II p. 303 .

2) 1. c. Band II p. 303. 
Das Gekiinstelte und Gestïckelte der Lehre ron der geschlechtlichen Zuchtwahl wird besonders klar, wenn man bedenkt, dass Darwin mit dieser Verschmelzung von Schönheit und Kraft seine ganzen vorherigen Ableitungen, in denen er mit so grosser Anstrengung die relative Überzalıl der Mämnchen darzulegen suchte, auf einmal wieder überflüssig gemacht hat. Damit aber diese Arbeit roch nicht ganz verloren ist. sagt el am Schluss dieses Abschnittes ${ }^{1}$ ): ,. Der in dieser Weise ron den kräftigeren Paaren beim Aufziehen einer grösseren Anzahl von Nachkommen erlangte Vorteil hat allem Anscheine nach hingereicht, geschlechtliche Zuchtwahl in 'Thätigkeit treten $\%$ lassen. Aber ein grosses Übergewicht an \%ahl seitens der Männchen würde noch wirksamer sein."

\section{$X$. Die von Darwin selbst besprochenen Einwände gegen seine Theorie.}

Darwin hat in der "Entstehung der Arten" den Einwänden gegen seine Zuchtwahllehre ein besonderes Kapitel gewidmet. Hier bespricht er einige wenige Einzelfälle, die, wie er meint, auf den ersten Blick mit seiner 'Theorie im Widerspruch stünden, der aber bei näherem Zusehen sofort rerschwinde. Meistens sind es solche Fälle, bei welchen Einwainde anf Grund der Unersichtlichkeit des die Selektion berlingenden Nutzens erhoben werden könnten. Solche Einwände sind natiirlich dem Darwinismus nicht sehr geführlich, weil ihm ja imme" die Ausrede übrig bleibt, dass wir in dem betreffenden Fall den Nutzen noch nicht kennen. Indes kïmnten doch auch für jene Rubrik noch ganz andere Beispiele, als die ron Darwin angeführten, beigebracht werden, bei welchen die stichhaltigkeit jener Ausrede sich doch zum mindesten als sehr zweifelhaft erweisen wïrde.

Darwin sagt: "Liesse sich irgend ein zusammengesetztes Organ nachweisen, dessen Vollendung nicht möglicherweise durch zahlreiche kleine aufeinanderfolgende M[odifikationen hätte

1) 1. c. Band I p. 239. 
erfolgen können, so müsste meine Theorie unbedingt zusammenbrechen". Er' vermag, wie er sagt, keinen derartigen Fall zu finden. Ich glaube trotzdem, dass es solche Beispiele giebt, z. B. die Einrichtungen, welche bei der Wasserpflanze Vallisnerin spiralis die Befruchtung ermöglichen. Die männliche Blüte löst sich zur Befruchtung vom Boden los und steigt an die Oberfläche des Vassers, wo die weibliche Blïte schwimmt. Hier ist eine allmähliche Entstehung dieser Verhältnisse auf Grund der Selektionstheorie nicht gut denkbar: die Eimrichtung'en, welche zur Loslösmng und zum Aufsteigen der männlichen Blïte fiilnren, mussten gleich anf einmal fertig sein. Zwischenstadien sind hier undenkbar, weil sie nicht den geringsten Nutzen gewähırt hätten.

Ein weiteres Beispiel bietet uns der Musculus trochlearis unseres Auges. War es von Vorteil, dass dieser Muskel in der bei den Säugetieren eingetretenen Weise verläuft, so müsste nach der Selektionstheorie auf eimmal diese komplizierte Einrichtung dagewesen sein. Die Rolle konnte zwar etwas weniger ausgebildet sein, aber das ganze Prinzip dieser Einrichtung musste auf eimmal entstehen, weil sonst der Muskel auch nicht die leiseste Amnäherung zu der für das Tier vorteilhaften Funktion gezeigt hätte, ein Selektionsprozess mithin nicht eintreten komnte. Solcher Fälle dürften sich wohl noch manche finden lassen.

Auch bei Besprechung der Ameisenkolonien, die Darwin in dem nämlichen Kapitel mit ziemlicher Ausführlichkeit behandelt, scheint er mir einige wichtige Punkte übersehen zu haben.

Dar'win erklärt die Entstehung geschlechtsloser unter einander verschiedener Individuen durch einen Selektionsprozess, in welchem die einzelnen Kolonien die Individuen sind, auf welche der Kampf ums Dasein wirkt. Jenachdem nämlich eine Kolonie nützliche (also eventuell auch unfruchtbare) Mitglieder hat, einen um so grössern Vorteil hat die Kolonie vor andern voraus; es wäre nun zwar denkbar, dass die Kolonien dergestalt im Selektionsprozess die Rolle der Individuen spielen, aber 
daraus folgt doch niemals, dass auch im Variierungsprozess die Kolonien als Individuen fungieren. Die Individnen, welche vermöge der Variiermng einander nicht völlig gleichen, sind und bleiben die Einzeltiele. Gerade infolge des Imstandes, dass es sich hier um Kolonien, also um eine grosse Anzahl von Individnen handelt, werden Unterschiede, wie sie die Varierung zwischen den Einzeltieren bedingt, zwischen den Kolonien, welche ja einen Turchschnitt durch eine grosse Anzahl variierender Elemente darstellen, so gut wie nicht rolhanden sein. Nicht in den ron Dalwin berïhrten, sondern hier in diesem Punkte, in der völligen Änderung des Verhältnisses der Variierung zum Selektiousprozess, liegt die Hauntschwierigkeit dieses Falles. Während sonst der Kampf uns Dasein und die Tariierung anf' den gleichen Gegenstand wirken. ist hier das Objekt ein verschiedenes, mol diejenigen Unterschiede, welche vermigge der Tariierung vorhanden sind, kionnen im Kampf ums Dasein nicht zul Geltung kommen.

Nun aber verlangt Dal win noch mehr. Er setzt, un die verschiedenen Formen der geschlechtslosen Ameisen zu erklären, ganz willkiurlich eine in Lanfe der Generationen eintretendt. Veränderung der Variierungsgesetze vorans. In einer Kolonie von älteren Generationen sollen viele mgleiche Arbeiter sein, die dam in späteren Generationen nach und nach gleich werden; d. l. es wird angenommen, dass in späteren Generationen die Neigung zur Variierung geringer geworden, beziehungsweise eine bestimmte Variierungsrichtung eingetreten sei. Diese unberechtigte Annahme folgte aber claraus, dass Dal'win sich nicht klar machte, dass hier das ums Dasein kämpfende und das variierende zwei verschiedene Individuen sind. Er nimmt irrtümlich die Kolonie anch als das variierende Individunm an und meint, auf diese Art aus einer Kolonie mit vielen mogleichen Arbeitern durch fortgesetzte Variierung und Selektion eine Kolonie mit wenigen verschiedenen Gruppen von Arbeiterfor'men ableiten zu kömnen. Da aber nicht die Kolonie, sondern das Einzeltier das variierende Element ist, so ist diese Rechnung falsch und setzt, wie gezeigt, eine bestimmte Variierungsrichtung 
ater Einzeltiere vorans. Das Eintreten einer solchen etwa als eine Folge der Selektion zu betrachten, wäre nun natürlich das Allerverfehlteste, da die Variierung von der Selektion ja nicht beeinflusst wird, die Erklärung durch Selektion vielmehr grade tlarin besteht, dass eine völlig regellose, nach allen Richtungen erfolgende Variierung voransgesetzt wird. Mit der Ammahme einer bestimmt gerichteten Variierung aber zieht sich die Selektionstheorie, wie wir dies jetzt schon oft goesehen haben, den Boden unter den Fïssen weg, indem sie sich. einer ihrer :wesentlichsten Voraussetzungen beraubt*).

Dar"win sagt in dem nämlichen Kapitel: "Liesse sich beweissen, dass irgend ein Teil der Organisation einer Species zum ausschliesslichen Besten einer andern Species gebildet worden sei, so wäre meine Theorie vernichtet, weil eine solche Bildung nicht durch natürliche Zuchtwahl erklärt werden kann". Im Anschluss an diese Stelle möchte ich eine Angabe mitteilen. die mir von mehreren Bienenzïchtern gemacht wurde, anf die jedoch noch kein sicherer theoretischer Schluss gegriundet werden kann, da ich die Richtigkeit jener Angabe noch nicht für völlig. verbürgt halte. Nach jenen Angaben soll nämlich die ausfliegende Biene während ihres ganzen Ausfluges nur Bliiten ron derjenigen Species besuchen, der die von ihr zuerst besuchte Bliite angehört. Verhält sich die Sache wirklich so, so ist dies .ein Beispiel obiger Art. Der Nutzen, den eine solche Einrichtung für die Bliite hat, ist einleuchtend. Die Selektionstheorie müsste auch einen Nutzen für das Tier fordern, der' schwer denkbar wäre. Aber wollte man selbst die äusserst unwahrscheinliche Annahme machen, dass rielleicht eine einheitliche Zusammensetzung der aufoenommenen Säfte für die Qualität des Honigs guinstig wirkt, oder dass es gar dem Magen der Biene zuträglicher ist, immer dieselben Säfte zu erhalten (ähnlich wie manche Personen zweierlei Bier nicht vertragen

*) Um aber anch bei Kolonien eine wirksame Selektion zu ermöglichen, reduziert die Selektion die Elternzahl. Vgl. We ismann. "die Allmacht der Naturziichtung" p. 40 und „Äussere Einfliisse als Entwicklungsreize" p. 43 n. 75. Difficile est, satiram non scribere. 
kömnen!), so bliebe doch noch Eines merklärt, nämlich das Hand in Hand gehen der beiden Vorteile, welche 'T'ier' und Pflanze aus der nämlichen Einrichtung ziehen. Ist die Einrichtung für das 'Tier zweckmässig, so kamn die Selektionstheorie diese Zweckmässigkeit vielleicht erklären, dass aber die Einrichtung vor allem äusserst zweckmässig für die Pflanze ist, bleibt merklärt. Es wäre wohl der Mühe wert, die fragliche Einrichtung aufs Genaueste zu untersuchen.

\section{Dass eine Auslese des Bessern stattfindet, ist nicht selbst- verständlich, sondern bedarf des Beweises.}

Im bisherigen Verlanf unserer Betrachtung haben wir vor. ausgesetzt, dass wirklich im sime Darwins ein Selektionsprozess die jedesmal am zweckmässigsten varierten Formen answählt und zur Fortpflanzung bringt. Wir haben sogar in der Einleitung gesehen, dass dies mit scheinbar mathematischer Notwendigkeit gefolgert werden kam. Inwieferm diese Notwendigkeit nur eine scheinbare ist, bleibt uns jetzt noch zu betrachten ïbrig.

Verfolgen wir eimmal das erste Beispiel, an welchem 1) ar:win die Wirkungsweise der natiurlichen Zuchtwahl erlïutert. Es wird angenommen, dass der Wolf durch äussere Umstände darauf angewiesen sei, sich ron einem schnellfüissigen 'l'ier \%. B. einel Hirschart zu ernähren. Die schnellfüssigen Wülfe werden num leichter den Hirsch erjagen, als die langsameren. Hierans folgert Darwin die Wahrscheinlichlieit, dass der langsamele Wolf untergehen wird, ohme sich fortgepflanzt zu haben, währem der schnellere Wolf sein Teben und seine Nachkommenseluatt sichert. Auf diese Art sollen schnellfüssige Wülfe gezüchtet werden. Sind nun diese Folgerungen lichtig? \%onnüchst kamn doch wohl nur gefolgert werden, dass dem langsameren Wolfe mancher Hirsch entgehen wird, den der raschere erbeuten wiirde. Aber von da bis zum 'Tode ist doch noch ein weiter Schritt. Mit demselben Recht wie die Darwi uschen Folgerungen kömnte man z. B. auch folgende ableiten: der langsamere IVolf ist dem schnelleren gegenüber im Vorteil, denn da er häufig ver- 
gebens Jagd auf Hirsche machen wird, so zwingt ihn del Hunger, ofter anf die Jagd zu gehen. Diese hänfigeren Leibesïbungen kräftigen den Körper, sodass er widerstandsfähiger gegen Strapazen und Krankheiten sein wird, als der schnelle Wolf, der sich nicht so viel Bewegung zu machen braucht und daher mehr Zeit im verweichlichenden dolce far niente zubringen wird, mithin dem langsamern Wolfe gegenüber weniger Aussicht haben dürfte, am Leben zu bleiben; anf diese Art werden langsame Wölfe gezüchtet.

Wer will num entscheiden, ob dieser oder der Darwinschen Folgerung die grössere Berechtigung zukommt? Beide einander vïllig entgegengesetzte Folgerungen haben offenbar gleichviel bezw. gleichwenig Wahrscheinlichkeit. Mindestens ist es TVillkür', eine dieser Folgerungen als selbstverständlich anzunehmen.

Es ist kein glückliches Beispiel, dieses mensa-Paradigma der Znchtwahllehre. Darwin hätte, wenn ihm das Beispiel eimmal besonder's behagte, weit besser gethan, dann doch wenigstens, statt am Wolf, am Hirsch den Selektionsprozess zı erläntern, denn da wïrde es sich wirklich um Leben und Tod handeln und nicht nur um mehr oder weniger leichte Beschaffung der Nahrung: der langsamere Hirsch hat an und fïr sich grössere Wahrscheinlichkeit, vom Wolfe erjağt zu werden, und wenn ihm dies Unglück zustösst, so ist er natürlich dem Untergange geweiht. Hier und in ähnlichen Fällen sieht die Sache ganz plausibel, ja geradezn selbstverständlich aus, und doch behaupte ich, dass sogar eine in dieser Weise stattfindende Selektion durchans nicht selbstverständlich, sondern dass sie eine willkürliche, erst des Beweises bediurftige Annahme ist.

Denn der Darwinismus nimmt in derartigen Fällen stillschweigend an, dass gegeniiber den die Existenz bedrohenden Gefahren die durch Variierung bedingte vorteilhafte Organisation die einzige oder wenigstens entscheidende Richtschnur ist, nach welcher die Anslese stattfindet. Diese Amahme ist aber eine willkiirliche, unbewiesene und sogar im höchsten Grarle unwahrscheinliche. 
Wenn einer Gefahr gegenïber mehrere verschiedene Vorteile iu die Wagschale kommen, so wird derjenige Torteil, der im Verhältnis zur Gefahr der grösste ist, natïrlich die grösste Sicherheit bieten, d. h. ron mehreren Individuen, von denen jedes einen andersartigen Vorteil der nämlichen Gefahr gegenïber besitzt, wird dasjenige Individum die grösste Clanne haben, der Gefahr zu trotzen, welches eben denjenigen Torteil besitzt, der im Verhältnis zur Gefahr der grösste ist. Bei dem geringen Unterschied, den die Selektion (wofern sie iiberhaupt (len Anspruch, eine Erklärung zu sein, erheben will) zwischen den einzelnen Individnen annelimen darf, kömnte ein Variierungsvorteil meistens nur damn von Belang sein, wenn el der einzige wäre. Der einzige ist el sichel nicht! Es kommen nehen ilnm mindestens andere Faktoren in Betracht.

Unter den von Gefahren bedrohten Individuen werden neben denen, die mit einem zufialligen Organis ations-Vorteil ansgeriistet sind, immer anch solche sein, denen ein zufälliger Situations-Vorteil zu Hilfe kommt. Bei einem Fisenbahnunglïck bleiben nicht diejenigen unverlet\%t, die zufällig die festesten Knochen laben, sondern diejenigen. welche znfällig die günstigsten Plätze eimehmen. Fin etwaiger Organisationsvorteil ist hier im Verhältnis zur Grösse der Gefahr viel zu klein, als diss el den weit grösseren Situationsrorteilen gegenïber in Betracht kommen kümnte. Er kïme nur in Betracht ceteris paribus, d. h. Wemn alle Individuen sich de' Gefahı gegenïber in völlig gleicher Sitnation befänden. Ein solches ceteris paribus setzt der Darwinismus iuberall voraus. Dies ist abel völlig nuberechtigt. Ich kam mir mu wenig Fälle denken, in denen eine zufällige Organisationsrariiermo einen Forteil bietet, dem ich nicht anch einen sitnationsworteil gegeniiberstellen könnte. So gut ich ammehmen kann, dass muter so und so viel Individnen immer einige sich finden, die gegen eine Gefahr durch irgend einen Variierungsrorteil besser geschützt sind, als die aindern, eben so gut kann ich sagen, dass auch nicht alle Individnen sich der Gefaln gegeniiber in gleich giunstiger Sitnation befunden haben. I)iejenigen, welche 
in der günstigsten Situation sind, haben mehr Chance, erhalten zu bleiben, als die, welche eine weniger günstige Situation einnehmen.

Soviel ist also jedenfalls sicher, dass das Resultat der Auslese keineswegs ansschliesslich von durch Variierung bedingten Vorteilen abhängt, sonder'n dass mindestens neben diesen noch andere Vorteile in Betracht kommen, welche von denen der ersten Art röllig verschieden sind. Gerade wie im Kampf ums Dasein der Völker, im Krieg; die Kugel nicht den Starken zu Ungunsten des Schwachen verschont, sondern denjenigen trifft, der ihr gegenüber in der ungünstigsten Situation steht, ohne dass seine persönlichen Eigenschaften dabei in Betracht kämen, so könnten im Kampf ums Dasein in der Natur vermöge der Situationsvorteile ganz gut auch solche Individuen zur Auswahl kommen, welche vermöge ihrer Organisationsvorteile die allerwenigste Chance hätten, erhalten zn bleiben. dergestalt, dass es recht wohl denkbar ist, dass die Organisationsvorteile völlig aufgehoben werden. Und dies ist das Wahrscheinliche.

Denn es ist sogar denkbar, dass gegenüber den Situationsvorteilen die Organisationsvorteile iberhaupt gar nicht in Betracht kommen. Die letztern kamn ich mir ja immer nur als ganz kleine vorstellen, während ich mir die ersteren unter Umständen als sehr bedentende denken kamn, sodass ihnen gegeniiber die Organisationsrorteile geradezu verschwinden.

Damit wollte ich durchaus nicht leugnen, dass unter Lmständen auch einmal die Organisationsvorteile den Ansschlag geben werden; dies wird immer da der Fall sein, wo die Situationsvorteile im Verhältnis zur Gefahr kleiner sind, als die Variierungsvorteile. Dieser Fall scheint mir vor allem denjenigen Gefahren gegeniber in Betracht kommen zn müssen, welche durch Parasiten, insbesondere durch Bakterien bedingt sind. Im Kampf mit diesen schleichenden Feinden dürften wohl Situationsvorteile kaum denkbar, jedenfalls aber gegenüber denen, die in der Natur des Organismus selbst gelegen sind, als verschwindende anzusehen sein. Auch den Einfliissen 
des Klimas gegeniiber werden wohl nur Variierungsvorteile den Ausschlag geben! dem anch hier sind keine Situationsvorteile denkbar; weil hier das ceteris paribus zutrifft, indem alle Individuen sich der Gefalı gegeniiber in genan der gleichen Lage befinden. In den weitans meisten Fällen dagegen glaube ich, dass die Variierungsvorteile im Verhältnis zu den Gefahren bedentend kleiner sind, als die Situationsvorteile: die Indiriduen mit letzteren werden gegeniiber denen, die nur Torteile der ersten Art besitzen, immer im Torteil sein. sie sind es daher, die in der Regel zur Auswahl kommen werden. Mindestens aber dïrfte in diesem Abschnitt gezeigt sein, dass die .. Anslese des Bessern" keineswegs so selbstrerständlich ist, wie allgemein angenommen wird. Ein Selektionsprozess findet unter allen Umständen statt, aber diejenigen Vorteile, welche sich auf die Nachkommen vererben können, sind nicht die einzigen, welche bei der Answahl in Betracht kommen.

An und fïr sich ist das Resultat der letztern Betrachtung von sehr geringem Belang. Denn wenn gezeigt ist, dass die Theorie von der Auslese des Bessern nichts erklärt, so lat die Frage, ob eine solche Anslese des Bessern ibberhaupt stattfindet, nur ein sehr untergeordnetes Interesse.

\section{Schluss.}

Wem wir zur Erkenntnis gelangt sind, dass die Ursache der Regelmässigkeit in der Veränderung organischer Formen nicht in der Selektion, sondern schon in Bedingungen gesucht werden muss, die der Selektion vorausgehen, so sind wir damit zugleich auf denjenigen Weg gewiesen, ron dem wir hoffen dürfen, dass er uns wohl ein Stiick weiter fuhlnen wird. Nicht in aprioristischen Theorien. wie die Zuchtwahllehre eine ist, sondern an der Hand der Erfahrimg, müssen wir den Gesetzen nachspüren, welche den Gestaltungsprozess beherrschen. Die direkte Beobachtung der Teränderungen selbst ist es aber wohl nicht, was uns einen befriedigenden Anfschhnss erwarten lassen kann, weil das Material, das mns hier zu Gebote stehen würde, 
im Vergleich zur Aufgabe nur ein verschwindend kleines sein könnte*). Dagegen sind wir im stande, aus denjenigen Thatsachen, welche uns die biologischen Spezialzweige liefern, in ausserordentlich vielen Fällen mit völliger Sicherheit Schlüsse zu ziehen auf Gesetze, welche im Lauf der phylogenetischen Entwicklung die Veränderung eines Organismus beherrscht haben.

Wir werden in dieser Weise die Geschichte der Organismen verfolgen. Wir werden z. B. mit völliger Sicherheit el'kennen, dass diejenigen Gebilde, aus denen die Pflanzenblätter entstanden, ursprünglich von einer völligen Einheitlichkeit im Abändern beherrscht wurden. Wir werden aber erkennen, dass diese Einheitlichkeit des Abänderns im Lauf del phylogenetischen Entwicklung nicht dieselbe geblieben, sondern dass eine regelmässige Differenzierung in mehrere speziellere Einheiten eingetreten ist, welche, weil sie der Selektion rorausgehen musste, nicht auf diese zurickgeführt werden kamm. Wir werden also erkennen, dass ganz bestimmte Blätter aus dem einheitlichen Verbande ausgetreten sind und unter speziellere Gesetze des Abänderns sich gestellt haben, dass auf diese Art eine bestimmte Anzahl unter einander regelmässig und einheitlich abändernder Blumenblätter, Staubgefässe und andrer' Bliitenorgane entstanden sind, welche, unter einander jeweilig von einheitlichen Änderungsgesetzen beherrscht, zugleich in ihrem Verbande eine nelle Einheit gebildet haben, die Bliite. Wir werden verfolgen, wie auch diese neuten Einheiten der Blïten unter Umständen ihre Selbständigkeit aufgegeben haben und mit einer bestimmten Zahl von ihresgleichen zu der neuen, nun wieder von einem neuen Gesichtspunkt aus regelmässig abändernden Einheit der kompositen Blüte zusammengetreten sind. Während also ursprïnglich alle Blätter ron einheitlichen Gesetzen des Änderns beherrscht werden, er-

*) Dass dennoch sogar die direkte Beobachtung des artrerändernden Prinzips, nämlich der „primären Zweckmässigkeit" möglich ist, wird in der dritten Abhandlung gezeigt. 
halten wir später ein Konglomerat von Blättern, die unter spezielle Gesetze des Abänderns treten: die Blïte. Trährend ursprïnglich alle Blïten einheitlich varieren, erhalten wir später Kouglomerate von Blïten, welche unter nelle Gesetr. des Abänderus treten.

Indem wir derart das ganze Reich der Organismen durchdenken und die Regelmässigkeit der Veränderungen, welche ror' Eintritt des Selektionsprozesses stattgefunden haben müssen, verfolgen werden, können wir vielleicht hoften, dereinst anch den Kräften der Veränderung auf die Spur zu kommen. Zunächst aber müssen wir die 'Thatsachen sammeh. 


\section{Zweite Abhandlung*).}

Herr Prof. Emery meint in seinem Angriff auf einen Teil des siebenten Abschnittes meiner "Beiträge zur Kritik der" Darwinschen Lehre", dass jedes konkrete (jedes in der Natur vorkommende) Variierungsinkrement eine Kombination von zahlreichen "Elementarvariierungen" sei. Für letztere gelte allerdings meine Behauptung, dass ein Plus ebenso wahrscheinlich sei, als ein Minus. Aber dass zufällig eine grosse Anzahl solcher Elementarvariierungen in so günstige Kónstellation kämen, dass ihre Kombination eine verbessernde „konkrete Variation" darstelle, dafür spreche nur geringe Wahrscheinlichkeit, so dass es bei Ausfall der Selektion "für eine ungeheure Zahl verschlechternder Variationsmöglichkeiten nur einige wenige verbessernde geben" werde, die Summe mithin notwendig zur Entartung führe. Bei rein „numerischen“ Änderungen könne an und für sich meine oben erwähnte Behauptung auch füir "konkrete" Variierungen gelten, aber - wie Em e ry gleich ninzufügt - auch da nicht einmal. Unter einer "numerischen" Änderung versteht Emery offenbar eine graduelle.

Herr Prof. Emery übersieht also vollständig, dass ich in jener Ableitung nur ex hypothesi spreche, dass ich mich auf

*) Diese Abhandlung erschien im „Biol. Centralblatt“ von 1. Juli 1891 als Erwiderung auf einen ebendaselbst Bd. X p. 449 fg. erschienenen Aufsatz von Emery. Dieser Emerysche Aufsatz, der seinem Inhalt nach keinerlei Widerlegung nötig gehabt hätte, war jedoch für mich nur der äussele Anlass, um an der Hand desselben einige in meiner ersten Abhandlung nur kur'z berïhrten Punkte eingehender zu besprechen. Desshalb durfte die Abhandlung hier nicht fehlen. 
den Standpunkt des Darwinismus stelle, mnd dass der ganze Dar'winismus in der' 'T'hat nul' mit graduellen Unter'schieden rechnet. Tede Darwinistische Deduktion sucht darzulegen, wie ein Vorliandenes im Laufe phylogenetischer Entwicklung grösser oder kleiner wird. Die Anfänge miissen vom Darwinismus, wenn el nicht zeigen kann, dass auch diese Anfange nur graduelle Änderungen, also keine Anfänge sind, immer vorausgesetzt werden, ein Punkt des Darwinismus, auf den ja schon mehrfache Angriffe gerichtet wurden. Stelle ich mich daher auf den Standpunkt des Darwinismus, speziell des extremsten und konsequentesten Darwinismus, wie ilm Weisma $n$ n vertritt (und anf diesem Standpunkte stehe ich dort, indem ich zu zeigen suche, dass $\mathrm{V}^{2}$ e is man mit seinen eigenen Toraussetzungen sich in Widerspruch setzt), so muss ich Darwinistisch rechnen.

Die Lehre von der natürlichen Zuchtwahl wird erläutert durch die Analogie der künstlichen Znchtwahl. Schon hierans ist ersichtlich, dass es sich nur um graduelle Anderungen handeln kamm. Der Züchter operiert nur mit solchen. Er will z. B. Schafe mit kinzen Vorderbeinen. Die Nachkommen eines Tieres variieren. Dass das Bein gröisser ist. ist eben so wahl'scheinlich, als dass es kïrzer ist, der '/iichter kömnte ebensogut auch lange Vorderbeine ziichten. I)ie passenden wählt el zur Fortpflanzung aus und erst dadurch wird die Summe der I)ifferenzen von Null verschieden. Statt des Züichter's wird num der Kampf ums Dasein in die Rechnung eingesetzt. So rechnet der Darwinismus ïberall, und so muss er rechnen. Wo ihm nachgewiesen wird, dass el nicht mit solchen graduellen Veränderungen rechnen kamn, ist er aufs 'Trockene gesetzt.

Wäre die Wahrscheinlichkeit einer niitzlichen Variierung wirklich so klein, wie Emery behauptet, wäre sie wirklich so klein, wie die Wahrscheinlichkeit, dass in dem Satz einel Druckseite durch beliebiges Ersetzen eines beliebigen Buchstaben durch einen beliebigen andern ein Druckfehler verbessert wird, dann kömnte sich der Darwinismus gleich von vornherein begraben lassen. Er könnte dam nicht mehr sagen: die Aus- 
lese des Bessern muss notwendig eine Steiger'ung des Nüitzlichen ergeben. Die erforderlichen Voraussetzungen wären dann noch viel verwickelter; es müsste dann auch noch übel' (den Intensitätsgrad ${ }^{1}$ ) des Selektionsprozesses eine Voraussetzung gemacht werden: er muss so hoch sein, dass die Summe aller überlebenden $\pm d x^{2}$ ) (unter denen vor Eintritt des Selektionsprozesses die ungehemre Mehrzahl negativ, das Vorhandensein positiver dagegen äusserst unwahrscheinlich war) eine positive Zahl wird. Der Kampf ums Dasein an und für sich nützt also noch gar nichts; erst wenn el jenen ganz bestimmten Intensitätsgrad erreicht, dann erst wirkt die Selektion verbessernd. Und wie hoch ist dieser von Emery geforderte Intensitätsgrad: Nimmt man an, ein Tier habe 40000 Millionen Kinder, von welchen nur 2 Individuen sich fortpflanzen, so wäre nach Emerys Rechnung dieser Selektionsprozess noch nicht einmal intensiv genug, um es wahrscheinlich werden zu lassen, dass diese $2 \mathrm{im}$ Durchschnitt sich irgendwie verbessert haben ${ }^{3}$ ).

1) Dieser Intensitätsgrad ist eine genau bestinmmte, wemn auch selten bestimmbare Zahl. Sie giebt das Verhältnis der erzeugten zu den sich fortpflanzenden Nachkommen an. Man könnte diese Verhältniszahl den Selcktionskoeffizienten nemnen.

2) Ich muss trotz der Einwendungen Emerys meine Schreibweise dx beibehalten. Sage ich, dass der Darwinismus mit dem Variierungsinkrement nur dann rechnen dürfe, wenn er von ihm keine bestinmte Grösse voraussetzt, sondern ihm gestattet, sich der Null beliebig zu nähern, und will ich dies durch ein mathematisches \%eichen ausdriicken, so ist das einzig richtige $\mathrm{dx}$. Ob die wirklichen Variierungsinkremente messbar sind oder nicht, ist dabei ganz gleichgiltig. Übrigens ist Emery im Irrtum, wenn er meint, alle seien messbar. Die wenigsten sind es. Die Differenz in der Disposition zur Tuberkulose zwischen zwei völlig gesunden Individuen ist \%. B. gewiss nicht messbar, und doch kann gerade hier eine, wenn auch noch so kleine Differenz, im Kampf ums Dasein den Ausschlag geben.

3) Wobei noch zu beachten ist, dass die Zahl 100 der Elemente, in welche Emery ein Organ sich aufgelöst denkt, selbstverständlich eine willkürliche ist, und dass diese Zahl der Wirklichkeit natürlich um so nïher kommen wird, je grösser sie angenommen wird. Wie enorm würde sich dann erst die Zahl der Kombinationen vermehren! Übrigens kommt es auf die Zahlen gar nicht an: das Wichtige ist, dass mit der Emeryschen An- 
Und dabei ist noch rorausgesetzt, dass die Selektion ron den 40000 Millionen wirklich ganz genau die 2 Besten herausgefunden liat. Dies wird natürlich nie der Fall sein. Denn je geringer die Prozentzahl der gïnstigen Tariierungen ist, um so weniger wird das Resultat del Selektion von Variierungsvorteilen, um so mell lagegen von Situationsvorteilen ${ }^{1}$ ) abhängen. Nehmen wir z. B. eine 'Tierklasse, bei welcher die Verhältniszahl der' erzengten und der erhaltungsfähigen Individuen der von Emery geforderten Zahl vielleicht am nächsten kommt: die Bandwiirmer. Nehmen wir also an, ein Bandwurm erzenge während semes ganzen Lebens 40000 Millionen Eier. Unter den abgehenden Eiern findet eine Selektion statt: nn' die, welche vom $/$ wischenwirt gefressen werden, kïnnen sich zur Finne entwickeln. Ls werden aber ungehener wenige gefressen, die meisten gehen ungefiessen zu Grunde. Wir haben also eine intensive Selektion. Wovon hängt es aber ab, ob das Ei gefressen wird? ( a usschliesslich von äussern Umständen. Die indiriduellen Eigenschaften der Eier kommen nicht in Betracht. Wir haben also hiel einen Selektionsplozess, bei welchem ein Einfluss der Variierungsorteile absolut ansgeschaltet ist, bei welchem ausschliesslich Situationsvorteile in Betracht kommen. Nur in Bezug auf die Resistenzfähigkeit künnten Variier'ungsvorteile von Relang sein, die wir aber ansschalten können, indem wir uns anf ein bestimmtes Anpassungsgebilde beschränken (was ïberhaupt bei jeder Darwinistischen Betrachtung nötig ist), \%. B. die Enıtstehung der Saugnäpfe etc. Dass unter den relativ wenigen gefressenen Eiern sich eines von den 2 mit einer in Bezng anf die Sangnäpfe vorteilhaften Keimesanlage befinde, ist äusserst unwahrscheinlich. Die gefressenen Embryonen kommen num „zur engeren Wahl". Nicht alle werden im fremden Organis-

nahme der Hypothesenkomplex, welchen die Selektionstheorie darstellt, um eine neue und zwar das Fundament betreffende Hypothese vermehrt würde.

1) Siehe Kapitel XI der ersten Abhandlung p. $35 \mathrm{ff}$. 
mus bleiben. Viele werden einfach abgehen. Bei diesem Selektionsprozess, der lange nicht so intensiv ist, als der erste, kömnen anch (aber keineswegs ausschliesslich) Variierungsrorteile mitwirken. Die soweit gelangten Finnen kommen nun zu einer noch engern Wahl. Nur diejenigen entwickeln sich weiter, deren Zwischenwirte gefressen oder gegessen werden. Diesen Selektionsprozess können wieder eine Unzahl der verschiedensten Faktoren beeinflussen. Mehr oder weniger grosser Geschmack an rohem Fleisch, mehr oder weniger grosse Achtsamkeit der Sanitätsbehörden, diplomatischer Notenwechsel über Grenzrerkehr: das sind alles Faktoren, die in Betracht kommen können. Eine schneidige Reichstagsrede kann unter Umständen über Tod und Leben von Tausenden von Bandwürmern entscheiden. Eine Klasse von Faktoren kommt aber ganz gewiss nicht in Betracht, das sind individuelle Vorteile der Finnen. Anch hier ist also die Wirkung der Variierungsvorteile ansgeschaltet. Unter den gefressenen oder gegessenen Finnen findet wahrscheinlich wiederum ein Selektionsprozess statt, bei welchem Variierungsvorteile (aber keineswegs ausschliesslich) mitwirken können. Von den 2 Individuen mit vorteilhaft variierten Sangnäpfen wird aber aller Wahrscheinlichkeit nach kein einziges zur letzten Wahl gekommen sein. Also selbst bei denjenigen Tieren, bei welchen die Überproduktion die grösste ist, künnte nach der Emeryschen Rechnung die Selektionstheorie zur Erklärung der Anpassungserscheinungen nicht mehr verwendet werden.

Ich bin über diesen Punkt übrigens nur deshalb so ausführlich gewesen, um mir die Gelegenheit zur Erörterung eines so interessanten Beispiels von Selektionsprozessen ${ }^{1}$ ), bei welchen

1) Wenn wir hier einen Fall haben, bei welchem wir zufällig ganz genau bestimmen können, welch ungeheuren Einfluss auf das Resultat der Selektion die Situationsvorteile haben, so wird jedem klar sein, dass dieser Einfluss auch da vorhanden sein wird, wo wir ihn nicht genau bestimmen können; es wird also klar sein, dass eine Ausschaltung del Situationsrorteile, wie sie der Darwinismus vornimmt, falsch, und die Annahme, dass die Tariierungsvorteile überall das Ausschlaggebende seien, hypothetisch ist. 
Variierungsvorteile ansgeschaltet sind, nicht entgehen zu lassen. An und für sich kommt es mir hier nur darauf an, zu konstatieren, dass Emery mit der von ihm angenommenen geringen Wahrscheinlichkeit einer guinstigen Variierung de n D a r'win istischen Standpunkt ${ }^{1}$, von welchem aus ich meine von Emery angegriffene Argumentation geführt habe, verlässt, und, indem er gezwngen ist, eine Voraussetzung ïber den Intensitïtsgrad des Kampfes ums Dasein zu machen, einen Standpunkt eimimmt, der jede Darwinistische Erklärung erschwert. Denn inn allgemeinen ist doch wohl jener Intensitätsgrad eine Grösse, für die wir keinen Massstab ${ }^{2}$ ) haben, und wenn wir eine bestimmte Grösse roranssetzen, so ist dies immer eine willkürliche Hypothese, rollends gar, wenn wir einen so hohen Grad roraussetzen wiirden, wie Emery dies miisste. Während also bisher duch wenigstens die Voranssetzungen des Darwinismus anerkannte Thatsachen (Variierung und Überproduktion) und nur seine F'olgerungen hypothetische waren, müste er numehr sogar einc Hypothese zur Voraussetzung machen.

Zu einer solchen Hypothese würde iibrigens in jedem Falle die Anerkemnung der WVeismannschen ${ }^{3}$ ) Lehre von der Pan-

1) Herr Prof. Enery scheint gan\% ïbersehen zu haben, diss I) it rw in selbst in ansführlicher Erörterung solch vereinzelten Gliichsfällen der Tariierung, denen Emery so grosse Bedeutung \%uspricht, die Brauchlatrkeit für die Selektionstheoric aberkennt. Es mögen solehe rorkonmen, aber der Darwinismus kamn nicht mit ihnen rechnes. Für diejenigen Variernng -inkremente, mit denen er rechnet, muss er vielmehr häufiges Aufteten voraussetzen. (Siehe Darwin, Entstehung der Arten, deutsche Ausigabe von Carus, 7. Aufl., S. $111 \mathrm{ff}$.)

2) Inmerhin ist klar, dass die Verhältuiszahl der erzengten Sachkommen zu den sich fortpflanzenden, welche Enery für alle Organisnen als Minimum annehmen müsste (20000 Millionen : 1), für keine Organismen zutrifft. Darwin selbst erklärt die \%ahl 99: 1 schon für cine extrent Schätzung wenigstens für höhere Tiere.

3) Eigentlich ist WTeismann mur der Crheber des Namens. Die Ansicht, dass die natürliche Zuchtwahl nicht nur die Bildnng, sondern auch die Erhaltung nützlicher Eigenschaften bewirke, wurde schon ron 1) arwin selbst ausgesprochen (1. c. S. 105). 
mixie den Darwinisten zwingen. Denn wenn schon zur Erhaltung eines Organes ein Kampf ums Dasein nötig ist, so muss ein heftigerer nötig sein zur Verbesserung desselben: es muisste also iber den Intensitätsgrad eine Toraussetzung gemacht werden.

Der besprochene Einwand Emerys richtet sich also durchaus nicht gegen mich, sondern gegen den Darwinismus. Ist der Einwand richtig, so besagt er nur, dass ich dem Darwinismus zu weitgehende Konzessionen gemacht habe ${ }^{1}$ ).

Ich habe zwar keine Veranlassung, den Darwinismus gegen Herrn Prof. Emery in Schutz zu nehmen, immerhin sei Eines bemerkt:

Nimmt man an, der Darwinismus habe Unrecht, wemn er meint, die Bildung von Organen sei durch graduelle Änderungen erfolgt, es seien vielmehr immer besonder's glïckliche Tariierungskombinationen nötig gewesen, so folgt daraus doch noch lange nicht, dass diese auch zur Erhaltung des betreffenden Organes erforderlich waren. Im Gegenteil! Es handelt sich ja in diesem Falle doch nur darum, dass die Kinder werden wie die Eltern. Nicht besonders günstige Variierungskombinationen, sondern möglichst wenig Variierung wird verlangt. Dass der Skatspieler ein Treffspiel mit 10 in die Hand bekommt, erfordert eine besonder's g'ünstige Kombination, für deren Eintreten eine bestimmte sehr kleine Wahrscheinlichkeit spricht. Hier hat allerdings die Wiederholung dieses Glïcksfalles keine grössere Wahrscheinlichkeit. Beim Organismus ist es aber denn doch wohl ein klein wenig anders. Dort spricht für Wiederholung eine sehr grosse Wahrscheinlichkeit, weil der' mächtige Faktor der Vererbung sie begünstigt. Emery setzt in den Darwinismus selbst da den Zufall ein, wo er sich bisher noch auf Gesetze stiitzte.

1) Um so auffallender ist Emerys Ankündigung, dass er nur eine einzige meiner Folgerungen zu kritisieren branche, um zu zeigen, wie fehlerhaft "gewisse" meiner Folgerungen begrïndet seien. Denn wenn Emerys Ausführungen richtig wären, so gäben sie allen meinen übrigen Folgerungen eine weitere wertvolle Stütze. 
Es haben wohl nocl wenige bestritten, dass die Nachkommen im Durchschnitt den Eltern gleich sind, d. li. dass Differenzen nach der einen Seite bei diesem Nachkommen im allgemeinen wieder ansgeglichen werden durch gleichwalırscheinliche Differenzen nach der andern Seite bei jenem Nachkommen. Höchstens hat hochgradiger Optimismus eine spontane Vervollknmmnungstendenz angenommen. Die 'Tlieorie von der Panmixie muss notwendig eine 'T'endenz zu. Verschlechterming annehmen.

Aber Herr Prof. Emery begründet ja diesen Pessimismus nicht nur mit der Seltenleit der von ihm verlangten gliicklichen Variierungskombinationen, sondern anch da, wo er solche nicht verlangt, wo es sich nämlich auch nach seiner Ansicht nur um graduelle Veränderungen handelt, wo also anch fïr iln Plus und Minus gleiche Walnscheinlichkeit haben, anch dia sucht el eine Verschlechtermostendenz zu begriunden durch Einfiihrung zweier Faktoren, die zur Degeneration jedes nicht mehr unter der schiitzenden Obhut der Selektion stehenden Organes führen sollen. Diese Faktoren sind die "Konknuren\% mit andern Organen" und - - der Atarismus.

Emery sagt: „A Aber gerade in diesem Falle verhïlt sicls die Selektion nicht indifferent, dem das unniitz gewordene Orơan hat mit einem Faktor zu kämpfen, welcher zn seiner Reduktion beiträgt, nämlich der Konkurrenz anderer, infolge der nenen Existenzbedingungen bevorzugter Orgame unn die Nahruugsstoffe"*.

Ich muss leider bekemnen, dass ich in der Nomenklatur der Logik nicht so bewandert bin, wie offenbar Herr Prof. Emery. Ich weiss daher nicht, ob es einen lateinischen Namen giebt für das Verfahren, das jemand einschlägt, wemm er bei Anfechtung einer Schlnssfolgermng die gesetzte Voraussetzung. unter welcher der Schluss erfolgte, einfach durchstreicht.

"Aber gerade in diesem Falle verluält sich die Selektion niclit indifferent.".

Heine von Emery angegriffene Argumentation hat zur Voraussetzung, dass Pammixie eintritt d. ll. dass die Selektion 
sich indifferent verhält, und Herr Prof. Emery wiederholt diese Voraussetzung ausdrücklich, indem er annimmt, dass das zu besprechende Organ ,der Einwirkung der natürlichen Auslese entzogen" sei. Und schon im zweitnächsten Absatz spricht er von Fällen, in denen sich die Selektion nicht indifferent rerhalten soll:

Oder hat Emery sich nur falsch ausgedrückt? Wollte er sagen, dass bei Ausfall der Selektion andere Kräfte eintreten. welche die Rückbildung herbeiführen? Dann hätte Emery allerdings nicht meine Voraussetzung, wohl aber meine Behauptung geändert, welche nur dahin ging, dass Panmixie keine Ruickbildung hervorbringe.

Obwohl also demnach der zitierte Satz des Herrn Emery mich nichts angehen kann, möchte ich ihn doch noch etwas näher betrachten.

Will Emer'y vielleicht sagen, die Rückbildung eines überflüssigen Organes sei für den Organismus vorteilhaft, weil jetzt wichtigere Organe sich dafür kräftiger entwickeln kömnten, und insofern verhalte sich die Selektion nicht indifferent, sondern führe eben die Rïckbildung herbei $\left.{ }^{1}\right)$ ? Dam bildet sich eben das Organ nicht durch Panmixie, sonder'l durch direkte Zïchtung zurïck, und der Fall entspricht eben nicht der Toraussetzung meiner Argumentation.

Oder will Emery vielleicht das Lamarckistische, nenerdings von Roux ausführlich behandelte Prinzip der „funktionellen Aupassung:" in jenem Satz als erklärenden Faktor einführen? Der Ausdruck "Konkurrenz anderer Organe um die Nahrungsstoffe" scheint ja auf Roux hinzudeuten. Wenn dem so ist, so entspräche also dieser Fall nicht meiner Behauptung: denn ob durch die direkte Wirkung der Funktionslosigkeit eine Riickbildung eintreten kamn, diese Frage habe ich in meiner

1) Diese Erklärung, auf welche We ismann hingewiesen hat (Über den Rückschritt in der Natur, S. 16) ist prinzipiell identisch mit der Dal'winschen (Maulwurfsaugen). Auch gegen sie gilt natürlich, waś ich gegen die Darinsche Erklärung eingewendet habe. 
Arbeit gar nicht behandelt, oder wenigstens nur nebenbei einen We ismannschen Gegenstand angeführt. Ausserdem stehe ich ja in jener'Ableitung auf dem Weismannschen Standpunkte, und von diesem aus greife ich die Weismannschen Folgerungen an. Es handelt sich um die Erklärung eines phylogenetischen Prozesses. T/ur Erklärung eines solchen erlaubt der Weismannsche Standpunkt natürlich nicht die Verwertung ler funktionellen Anpassung. IV e ismann begründet ja in jener Schrift, für welche Emery eine Lanze bricht, seine Erklärung unter anderm ganz besonder's damit, dass dieselbe auch in Fällen, wo von einer direkten Wirkung der Funktionslosigkeit gar keine Rede sein kann, Befriedigendes leiste. Dort finden sich Beispiele von Rückbildungen, bei deren Betrachtung auch Herr Emery nicht mehr hätte im Zaweifel sein künnen. das: es sich einerseits um graduelle Verinderungen handle, während andrerseits von einer direkten Wirkung der Funktion bezw. des Austalls derselben nicht gesprochen werden könne, \%. B. die Rückbildung des Stiels "funktionslosel“" Stanbfäden ${ }^{1}$ ). Die Grösse des Stieles wird natürlich bei den Nachkommen variieren, aber es ist gleichviel Wahrscheinlichkeit vorhanden, dass der Stiel grösser, als dass er kleiner wird; findet daher keine Selektion statt, so ist die Summe der Differenzen gleich Null, die Durchschnittsgrösse bleibt dieselbe. Zu dieser einfachen Überlegmng wird uns die Betrachtung jedes konkreten Falles nötigen.

Nun lässt aber Emery bei funktionslosen Organen die Ruickbildung anch noch durch den A tavismus beguinstigt werden. Über diesen Punkt will ich mich kurz fassen. Demn eine E1scheinung; die wir völlig unregelmässig ab und zu auftreten sehen, als bewirkenden Faktor zur Erklärung einer regehmässior verlaufenden Erscheinungsreihe zu verwerten, dieser (iedanke kommt mir so unheimlich vor, dass mir beinahe der Mut fehlt. ihm so weit nachzugehen, um zu finden, dass nach dieser Kalkulierung die durch mehrere Generationen bereits eingeleitete

1) 1. c. S. 17.

WV olff, Beiträge zur Kritik ler lorwinschen I,the. 
Rïckbildung wieder annulliert, und das Rückgebildete zum frïhern Grad der Ausbildung zurïckgebracht werden müsste, und dass ausserdem das biogenetische Grundgesetz ${ }^{1}$ ) beweist. dass die Rückbildungen nicht durch "Hemmung in der Ontogenese" entstanden sein können. -

Ich habe mir die grösste Mühe gegeben, den Aufsatz des Herrn Prof. Emery zu verstehen. Wenn ich in demselben trotzdem, auch mit dem besten Willen, keine Widerlegung der von ihm angegriffenen Ausfïhrung erblicken kann, so will ich. die Möglichkeit, dass ich nicht zum vollen Verständnis emporgedrungen, offen haltend, jetzt annehmen, Emery habe vollkommen Recht, und mein Angriff auf die Lehre von der Panmixie sei von ihm erfolgreich zuriickgewiesen. Was folgt daraus? Daraus würde folgen, mein Beweisversuch, dass die Lehre ron der Panmixie sogar vom Standpunkt des Selektionstheoretiker's falsclı sei, wäre misslungen. Würde daraus aber folgen, dass diese Lehre richtig ist? Durchaus nicht! und sie wïrde damn immer noch widerlegt durch das, was ich gegen jede selektionstheoretische Erklärung der Rückbildungen eingewendet habe: durch das biogenetische Grundgesetz.

Aber ich bin bereit, Herrn Prof. Emery noch grössere Zugeständnisse zu machen. Ich will ihm nicht nur zugestehen. seine Bekämpfung meines Angriffs anf die Lehre von der Panmixie sei gelungen, sondern ich will ihm sogar einräumen, diese Lehre sei vollkommen richtig. Wir wollen einmal unter dieser Voraussetzung das Verhältnis der Panmixie zur Selektionstheorie etwas näher betrachten.

Für jeden, der sich den Grundgedanken der Selektionstheorie auch nur einigermassen klar gemacht hat, kann kein Zweifel dariiber bestelien, dass die natürliche Selektion immer nur ein einziges Anpassungsgebilde, niemals aber zwei oder gar noch mehr zu gleicher Zeit zïchten kann. Es kömmen z. B. Auge und Ohr nicht gleichzeitig geziichtet werden, demn sonst

1) Darunter verstehe ich hier bloss die Erscheinung, dass rïckgebildete Organe so häufig sich ontogenetisch anlegen und wieder zurückbilden. 
miissten ja die ausgelesenen Individuen mit den besten Augen zugleich auch diejenigen mit den besten Ohren sein, eine Voranssetzung, die wir um so weniger machen dürfen, als dieselbe ja auf alle ïbrigen Organe ansgedehnt werden miisste. Die Naturziichtung wird sich immer auf die Züchtung desjenigen Organes verlegen, dessen bessere Ausbildung für das Tier den grösseren Vorteil bietet $\left.{ }^{1}\right)$. Ist ein gutes Auge nuitzlicher, als ein gutes Ohr, so sind die Individuen mit den besten Augen denen mit den besten Ohren gegeniiber im Vorteil: sie werden geziichtet. Während also das Auge gezuichtet wird, steht das Ohr nicht unter dem Einfluss der Selektion, also unter dem Einfluss der Panmixie. Unter diesem Einflusse stehen aber sümtliche Organe mit Ausnahme des einzigen, welches gerade geziichtet wird, sie fangen daher alle an, einen Rückbildungsplozess einzugehen. Sobald num eines der nicht geziichteten Organe bereits so weit rïckgebildet ist, dass der Zustand desselben eine Gefahl für den Organismus in sich schliesst, alsdann wird sich die Naturziichtmng diesem Organe zuwenden, demn dam ist eine bessere Ausbildung dieses Organes ein grösserer Vorteil als die des andern. Die Selektion iiberlässt also dieses letztere seinem Schicksal, d. h. der riickbildenden Panmixie, unter deren Einflusse die andern Organe immer noch stehen.

Wem die Absurdität dieser ganz unvermeidlichen Konsequenzen noch nicht einleuchtet, der möge sich die sache an einem Bilde versinnlichen. Wemn ein Lehrer eine Klasse von Schïlern zu unterrichten hat und dabei so verführt, dass er immer einen Schüler zu sich auf sein Zimmer nimmt und dort mnterrichtet, unterdessen aber die ïbrigen treiben lässt, was sie wollen, so wird er bei einer Inspizierung durch den schulrat

1) Jedes Gebilde, welches durch Naturzüchtung hervorgebracht ist, auch wenn es jetzt von untergeordneter Bedeutung ist, muss einmal Generationen hindurch, d. h. so lange als die Selektion zu seiner Herstellung brauchte, das allerwichtigste gewesen sein, eine Konsequenz, die allein genïgt, den ganzen Darwinismus ad absurdum zu führen. 
mit seiner Klasse wenig Staat machen können, weil die Schïler weit mehr Zeit auf das Vergessen, als anf das Behalten und Lernen verwendet haben. Sie werden daher nicht nur das, was sie bei diesem Lehrer in den wenigen Einzellektionen, sondern auch das, was sie in den frïhern Klassen gelernt hatten, vergessen haben. Genau so beim Organismus. Alle Organe stehen eine weit längere Zeit unter dem Einflusse der Panmixie, als unter dem der Selektion; wenn also die Panmixie einen Einfluss ausuibt, so wird dieser Einfluss der ïberwiegende sein, und wenn dieser Einfluss dem der Selektion entgegengesetzt ist, so wird der Einfluss der Selektion gänzlich aufgehoben werden, d. h. der rïckbildende Einfluss würde die Oberhand behalten, das ganze Tier müsste sich mit Stumpf und Stiel - zurückbilden, ein Vorgang, bei welchem die Panmixie zu vergleichen wäre einem Feuer, das ein Dorf ergriffen hat, die Selektion dagegen einer Fenerwehr, welche mit der Spritze immer wieder an dasjenige Haus fährt, aus dem gerade die stiärksten Flammen herausschlagen. Diese Fenerwehr wird gewiss nicht viel von dem Dorfe retten.

Der Darwinismus muss also, wenn er der Absurdität dieser Konsequenzen entgehen will, notwendig annehmen, dass diejenigen Organe, welche jeweilig nicht unter unter dem Einflusse der Selektion stehen, ruhig und umbeschadet warten können, bis die mütterliche Sorgfalt der Selektion, welche sich immer nur einem ihrer Kinder widmen kann, sich ihrer wieder annimmt. Das heisst der Darwinismus muss annehmen, dass die Panmixie keinen Einfluss auf die Organisation hat.

Da aber die Variierung eine Thatsache ist, so muss er annehmen, dass günstige und ungünstige Variierung die gleiche ${ }^{1}$ ) Wahrscheinlichkeit haben, womit ein weiterer Beweis geliefert ist, dass der

1) Ist man, wie Emery, der Ansicht, dass ungïnstige Varierungen grössere Wahrscheinlichkeit haben als giunstige, so muss man hicraus allein dic Unrichtigkeit der Selektionstheorie folgern. 
Darwinismus nur mit graduellen Veränderungen rechnen kann.

Die Lehre von der Pammixie und die Selektionstheorie vertragen sich nicht mit einander. Ans der Richtigkeit der einen folgt die Falschheit der andern. Und insofer'n die Selektionstheorie eigentlich die Voranssetzung zur Lehre von der Pammixie ist, vernichtet diese letztere sich selbst durch ihre blosse Existenz. Ihre Bejahung schliesst ihre Verneinung in sich, d. h. sie leidet an einem unlïsbaren imeren Widerspruch. 


\section{Dritte Abhandlung**).}

Vor jetzt gerade vier Jahren habe ich im "Biologischen Centralblatt" eine Reihe von Gründen darzulegen versucht, aus denen mir die Unhaltbarkeit der D ar w in schen Selektionstheorie hervorzugehen scheint. $\mathrm{Ob}$ meine Arbeit einigen Nutzen gestiftet, d. h. ob sie die Aufgabe, das Dogma der Selektionstheorie zu beseitigen, der Lösung, wenn auch nur um einen minimalen Schritt uäher zu bringen geholfen hat, darüber habe ich kein sicheres Urteil; aber es will mich fast bedünken, als ob es so sei, und ich schöpfe diese Vermutung nicht aus del' meiner Arbeit zu Teil gewordenen offenen Beachtung; deren Geringfügigkeit nur einen mit den Verhältnissen nicht Vertranten entmutigen könnte,-sondern ich schöpfe sie aus der verstohlenen Beachtung, aus den heimlichen Verschanzungsversuchen gegen meine Einwände, welche ich im Darwinistischen Tager wahrnehme.

Wie dem aber anch sei - Thatsache ist, dass im Lauf der letzten Jahre das Gleichgewicht, in welchem die Selektionstheorie sich in der Schwebe hält, ein bedentend labileres geworden ist. Es mehren sich die Anzeichen, dass die Episode des Darwinismus überwunden werden wird. Als solche Anzeichen betrachte ich weniger die wachsende Zahl derjenigen. deren Stimme sich gegen die Theorie erhebt, als vielmehr ror' allem die Thatsache, dass schon mehr als einer, 1 m mit Schopenhauer zu reden, ,still davonschleicht und thut, als

*) Diese Abhandlung, welche die in den beiden vorigen Abhandlungen indirekt dargelegte primäre Zweckmässigkeit nummehr direkt zu elweisen sucht, erschien im „Biol. Centralblatt" vom 1. Sept. 1894. 
wäre er nicht dabei gewesen". Aber wem anch diese Zeichen noch nicht deutlich genug reden, den verweise ich auf die neneste Schrift ${ }^{1}$ ) Weismanns, welche,.die Allmacht der Naturzüichtung" betitelt ist, und welche die Ohmmacht der Selektionstheorie verkindigt. In dieser Schrift wird zugegeben, dass man sich in keinem einzigen Falle die Entstehung einel zweckmässigen Einrichtung durch den Selektionsprozess wirklich vorstellen kann; es wird verzichtet auf die direkte Terteidigung des Darwinismus, dieser wird nur noch zu halten gesucht durch die Unzulänglichkeit des Lamarckismus. Daraus, dass Lamarckismus und Darwinismus bis jetzt die einzigen zur Erklärung der organischen \%weckmässigkeit anfgestellten 'Theorien sind, werden aber doch wohl nur Wenige folgerm, dass eine von diesen beiden 'Theorien die richtige Errkiärung enthalten muss, und dass es ausser ilmen iiberhaupt keine andre mehr geben kann. Und wenn der Tamarckismus beim Probieren auf Einzelbeispiele versagt hat, so werden wir nicht glauben. uns deshalb ein entsprechendes Erproben des Darwinismus ersparen zu können; wir werden ms nicht für berechtigt halten. die Darwinistische Formel num einfach iberall maschinemmiissig einzusetzen, ohne uns um das Einzelne zu kümmern, und ohne davor zurïckzuschenen, wenn es Not thut, auch einmal die Selektion durch Zuchtwahl zu erkiairen; und wir werden uns nicht ïberleden lassen, dass jetzt jedes Erklürungsprinzip. welches irgendwie in Verbindung mit Selektion gebracht ist, -- sei es auch nur dadurch, dass letztere gestrichen wird, wie in der Panmixie - , mit seiner Aufstellung auch schon als wirkend nachgewiesen" ist, sondern wir werden uns nach wie vor für verpflichtet halten, der Darwinistischen Erklärungsweise im allgemeinen wie im speziellen nachzugehen.

Grosse Meinmosverschiedenheit herrschte bekanntlich ron jeher ïber den eigentlichen Erklärungswert der Darwinschen 'Theorie, und worin das eigentliche Erklärungsmoment der Theorie besteht, dariiber laben sowohl Anhänger als auch Gegner der

1) Weismann, Die Allmacht der Naturzïchtung. Jena 1899. 
Zuchtwahllehre sich nicht immer die nötige Klarheit verschafft. Es wird dem Darwinismus oft der Vorwurf gemacht, er erkläre nur, dass Unzweckmässiges zu Grunde ging, nicht aber, dass \%weckmässiges entstand, ein Einwand, der keineswegs so ohne weiteres stichhaltig ist.

Es ist wahr: wemn wir sagen, die Selektion schafft Zweckmässiges dadurch, dass eben nur das Zweckmässige erhalteu wird, das andre zu Grunde geht, so wird in dieser Fassung das Zweckmässige natïrlich vorausgesetzt aber nicht sein Zustandekommen erklärt. Dass Zweckmässiges überhaupt da war, ist im höchsten Grade unwahrscheinlich und unverständlich. Mochte auch unter den vielen Variierungen manchmal etwas. \%weckmässiges zufällig vorgekommen sein, so ist die Wahrscheinlichkeit eines solchen Eintreffens so gering, dass ich nicht das Recht habe, diesen Faktor als einen gegebenen in meine Rechnung einzusetzen. Diese Wahrscheinlichkeit sucht mun der Darwinismus dadurch zu vergrössern, dass er alle möglichen Fälle annimmt, unter welchen natürlich auch das Zweckmässige als Spezialfall enthalten sein muss. Der Darwinismus sucht also den Treffer sich dadurch zu sichern, dass er den ganzen Glückshafen mit nach Hause' nimmt.

Um ein Beispiel zu nehmen: es sei von Vorteil, dass die Schnabelform entsteht, wie sie beim Kreuzschnabel vorhanden ist. Der Darwinismus nimmt an, dass durch glïckliche Variierung ein bezw. mehrere oder sogar viele gekrenzten Schnäbel auftraten. Sagt nun der Gegner: das spontane Auftreten einer Schnabelkreuzung scheint mir so unwahrscheinlich, dass ich diese Voraussetzung eben nicht zugebe, so antwortet der Darwinist: unter allen möglichen Schnabelvariierungen ist auch der gekreuzte, darf ich alle, so darf ich auch diesen voraussetzen; da aber die Variierung, wie die Beobachtung lehrt, nach allen Richtungen beliebig wirkt, so sind alle Variierungen möglich, folglich darf ich auch jene spezielle voraussetzen.

Der Gegner würde jetzt vielleicht so erwidern: Gewiss, möglich sind alle Variierungen, aber gegeben ist deren doch immer nur eine begrenzte Anzahl. Die Zahl aller möglichen 
Variierungen ist $=\infty$, die /ahl der gegebenen ist eine endliche Grösse. Die Wahrscheinlichkeit des Eintretens einer speziellen zweckmässigen Variierung (in mserm Beispiel der zweckmässigen Schnabelkrenzung) ist Endliches dividiert'dn'ch Unendliches, d. h. eine Zahl, welche sich der Null olne Ende nähert; mithin ist die Wahrscheinlichkeit, dass mnter den gegebenen Fällen sich eine gïnstige Variierung befindet, so ungehener klein, dass nicht die geringste wissenschaftliche Berechtigung besteht, den betreffenden Fall voranszusetzen. Und mm wiirde allerdings demjenigen Darwinisten, welchem die Kühnheit fehlte, die Zahl der ihm zur Verfügung stehenden Tariermugen einfach $=\infty$ zn setzen, wohl kanm etwas andres iibrig bleiben, als sich darauf zn berufen, dass es eine siorte von Variierungen giebt, bei denen die Zahl der gegebenen Fälle gross genug ist, mm alle möglichen zu enthalten, gross genug also, um die Voranssetzung jedes einzelnen wissenschaftlich zu rechtfertigen, nämlich diejenigen Variermugen, welche mur in gradnellen Terändermugen bestehen, bei denen es sich also nur darmu handelt, dass ein Vorhandenes grösser oder kleiner wird. Hier ist die Zahl der möglichen Fälle gleich 2, die der gegebenen ebenfalls, die Wahrscheinlichkeit, sich unter den gegebenen zu befinden, ist also fïr jeden der moglichen Fälle gleich 1.

In der 'That, diese Konzession, dass die Zuchtwahllehre, wofer'n sie nur mit gradnellen Veränderungen rechnet, ein Moment in sich trägt, welches sie - falls ihre Anwendung sonst gerechtfertigt wäre - zn einer Erklärung befühigen könnte, miissen wir dem Darwinismus machen, damit el sich nicht iiber ungerechte Behandlung beklagen kamn, wobei man allerdings darauf gefasst sein muss, dass er sich sogar gerade iiber diese ihm gemachte Konzession beklagt; demn als ich in meinem Angriffen der Selektionstheorie dieses Zngeständnis gemacht hatte, erhob sich ein Darwinist ${ }^{1}$ ) und protestierte gegen diese willkürliche Voraussetzung. Er hat sich damit natiirlich den

1) Emery, Biol. Centralblatt, Bd. X, S. $742 \mathrm{ff}$. 
Ast, auf dem er selber sitzt, abgesägt. Willkïrlich gemacht ist diese Voraussetzung ja allerdings, aber natürlich nur zu Gunsten des Darwinismus, sie ist ein letzter, ihm noch eingeräumter Schlupfwinkel, und die Sache wird dadurch noch humoristischer, dass $\mathrm{W}$ eismann, was ich damals gar nicht wusste, diesen Schlupfwinkel schon lüngst' ${ }^{1}$ ) für sich in Anspruch genommen hatte, aus dem ihn Herr Emery verjagt, um ihn zu verteidigen.

Es ist wahr,haft schmerzlich zu sehen, mit welcher Flïchtigkeit nicht bloss Emery, sondern sogar Forscher von der Bedeutung Wilhelm Roux's die hier berührten Probleme glauben behandeln zu diirfen. In der Art und Weise, wie der letztgenannte Forscher den Darwinismus gegen meine Einwände zu verteidigen ${ }^{2}$ ) sucht, offenbart derselbe leider nicht denjenigen Grad von Grïndlichkeit, welchen die Sache beanspruchen darf. Was soll man dazu sagen, wemn Roux die We ismannsche Ableitung der Rückbildungen durch Wegfall der Selektion mit der Bemerkung verteidigt, dass ,.die Auslese“ (deren Fehlen ja die betreffende Wirkung hervorbringen soll) "hier eine ïberaus grosse ist und daher wohl die von Weismann angenommene Wirkung haben kann"? Oder was soll man erwidern, wenn die nachgewiesene gesetzmässig komplizierte Variierung dadurch aus der Welt geschafft werden soll, dass man sie zuriickprojiziert auf die Anlage im Keimplasma unter Berufung auf unsre Unkenntnis darüber, wie hier die betreffende Gesetzmässigkeit (deren Vorhandensein nicht gelengnet werden kamn) ihren Ausdruck findet? Ein Versteckenspiel, eine Flucht ins Dunkle ist es, wemn man vorschreibt, dass wir , aus den gemeinsamen Variationen mehrerer entwickelter gleicher Teile" "bloss auf ein enges entwicklungsmechanisches Verkuüpftseins der virtuellen Vorstufen dieser erst später gegliederten Bildungen schliessen" dürfen. Denn wenn man zugeben muss und zugiebt, dass das Gesetzmässige der Variie-

1) Weismann, Ueber die Vererbung. Jena 1853. S. 53.

2) Roux, Entwicklungsmechanik (Ergebnisse der Anatomie und Entwicklungsgeschichte ron Merkel und Bonnet, Band II, S. $423 \mathrm{fg}$. 
rung im Keim schon ,.irgendwie potentia." enthalten ist, so muss man sich doch sagen, dass damit dasjenige, um was allein es sich handelt, zugegeben ist. und dass das "Wi e." gar nicht mehr in Frage kommt. Dasselbe gilt natiulich auch ron den gesetzmässigen Korrelationen, über welches ich das. was $\mathrm{R}$ юn in diesem Punkte zu entgegnen wäre, schon im voralus elörtert habe $\left.{ }^{1}\right)$.

Aber wir wollen uns hier gar nicht lange damit anfhalten, den Darwinismus auf die Richtigkeit seiner Einzelroraussetzungen zu prïfen, wir wollen die Sache ron einem etwath allgemeinern Gesichtspunkt auffassen, wollen uns hier\%u eine scheinbare Abschweifung erlauben und uns zunächst einmal dir. Frage vorlegen: was ist denn eigentlich ein Organismus? IV as ist Leben?

Ueber unser Unvermögen, diese Frage zu beantwoltell, herrscht wohl allgemeine Einigkeit. Denn selbst msre Physinlogen, welche wissen wollen, dass das Leben ein phrsikalischchemischer Prozess ist, wissen dies 11 ', sozusagen, programmmässig. Sie haben sich das Resultat ihrer Rechnung im ruraus selbst gegeben und suchen nun nachträglich den $\mathbb{T}_{\mathrm{eg}}$, aut dem die geforderte Lösung heranszubringen ist. W'ie weit man aber noch ron des Rätsels Lüsung entfernt ist, zeigt der. Umstand, dass es noch nicht eimmal gelungen zu sein scheint, das Ratsel in klare Worte zu fassen, eine Definition des Lethens zu geben.

Nun wäre zwar, künnte es scheinen, der Mangel einer richtigen Definition noch das kleinste Ungliick. Was nntel' .Organismus", unter "Leben" verstanden wird, weiss pin .Jeder. Man hat oft gestritten. ob ein Körper' dem 'L'ier'- oder Pflanzenreich angehöre, aber ob ein Körper der belebten oder der' unbelebten Natur beizuzählen sei, darïber tauchten - auch die Geschichte des Eoroon Canadense, selbst die des Baflybiris Hackcli ändert hieran nichts - noch keinerlei Meinungsvelschiedenheiten auf. Praktisches Beduirfnis ist die gesuchte

1) p. ․․… 
Definition nicht, aber wie dürfen wir hoffen, ein Rätsel zu lösen, das wir noch nicht einmal auszusprechen gelernt haben?

Der Organismus hat mit anorgischen Gebilden Form und Stoff gemeinsam, d. h. er hat räumliche Ausdehnung, ist ein Körper wie sie und besteht aus denselben Substanzen, die wir anch in der anorganischen Natur finden. Jeder lebende Körper kann mit Leichtigkeit in einen toten verwandelt werden. Könnten wir einen toten Körper in einen lebenden verwandeln, so wïssten wir wahrscheinlich das Wesen des Lebens anzugeben; aber wenn wir einen lebenden Körper in einen toten verwandeln können, sollte es uns dann nicht möglich sein, die hierbei eintretenden Veränderungen zu bestimmen?

Die Gewebe eines Tieres gehen nach dessen Tode rasch Veränderungen ein, die hervorgerufen werden durch die Einflïsse der Aussenwelt. Indem wir die Einflïsse der Aussenwelt geeignet modifizieren, können wir die Veränderungen hintanhalten. Indem wir z. B. das Fleisch in kalte Umgebung bringen, können wir dasselbe vor den Einflïssen der Aussenwelt schïtzen. Der organische Körper bedarf also nach seinem Tode eines Schutzes, um nicht infolge der Einflïsse der Aussenwelt verändert zu werden. So lange sie lebte, bedurfte die organische Materie gegen diese nämlichen Einfliusse des schutzes nicht, der Schutz lag in ihr, sie war diesen Einwirkingen angepasst.

Nicht allenthalben zeigt sich nach dem Aufhören des Lebens eine solch auffallende Veränderung. Haare können lange unverändert aufbewahrt werden. In den osteologischen sammlungen finden wir die Kalkmassen, welche einstige Organismen stiitzten, in den Insektensammlungen die Chitinhiillen frïherer Lebewesen. Aber anch diese Teile sind gegen die Einflïsse der Aussenwelt lange nicht mehr so geschiitzt, als zu der Zeit, wo sie Bestandteile des lebendigen Organismus waren. Durch künstliche Mittel muss den Einflïssen der Aussenwelt begegnet. werden, und was schliesslich erhalten bleibt, war schon toter Bestandteil des lebenden Körpers. 
So viel ist sicher, die organische Materie verliert mit dem Tode die Anpassung an die Aussenwelt, in dieser Anpassung muss also etwas für das Leben Charakteristisches liegen.

Und in der 'That, dasjenige, was uns die Lebensel'scheinungen als etwas Andersartiges, in der anorganischen Natur nicht Vorkommendes erscheinen lässt, ist ganz ausschliesslich das Verhalten gegeniiber der Aussenwelt.

Jeder Körper wird von seiner Umgebung beeinflusst, jeder setzt diesen Einflïssen einen bestimmten Widerstand entgegen; aber der leblose Körper setzt ilmen einen immer gleichen Widerstand entgegen, der Organismus dagegen kam diesen Widerstand den Einfluissen der Aussenwelt entsprechend verändern. sei es dass er befühigt ist, den widrigen Einflüssen zu entfliehen, oder die eigene Form zu änder'n, so lass dem Angriff besser widerstanden wird, oder denselben zu paralysieren, oder gar einen bereits erlittenen Schaden wieder auszubesser'l. Also auch die Erscheinungen der' Wundheilnng' und der Regeneration verloren gegangener 'Teile, diese Tsebenserscheinnngen $\approx \alpha \tau^{\prime} \vec{\varepsilon} \xi o \% \eta$ sind nichts andres, als Anpassungserscheinungen.

Bei jeder Verändermng, die der Organismus an sich rornimmt, z. B. um einem Angrift von anssen zn entgehen. oder um irgend eine Einwirkung der Umgebung zu seinem Nutzen zu verwenden, wird Bewegung frei. Damit aber Kräfte frei werden, mïssen Verbindungen zerfallen, d. h. Stoffe des Orgatnismus verbraucht werden. Diese im Kampf mit der Aussenwelt verlorenen Stoffe kamn num der Organismus durch Assimilation der in der Aussenwelt vorgefundenen Stoffe regenerieren. Da die Einwirkmng der Aussenwelt eine beständige ist, so ist der Verlust und damit der Er'sat\% ron Stoffen ein beständiger, und es resultiert hieraus ein beständiger Stoffwechsel, der also nichts andres ist, als eine Anpassungserscheinung.

Dass Sensibilität und Perzeptionsfähigkeit Anpassungen an die Aussenwelt sind, braucht nicht herrorgehoben zu werden, 
iiberhaupt wird jeder bei einigem Nachdenken leicht erkennen, dass alle Lebenserscheinungen weiter gar nichts sind, als Anpassungserscheinungen, d. h. Erscheinungen jener ganz eigenartigen Wechselbeziehung zwischen Organismus und Aussenwelt, die uns als organische Zweckmässigkeit erscheint. Auch die Lebensthätigkeit der niedersten Organismen zeigt dieses Verhalten, ja, dieses Verhalten ist eben das Einzige, was die Lebenserscheinungen von den Erscheinungen in der organischen Natur unterscheidet. Die zweckmässige Anpassung ist das, was den Organismus zum Organismus macht, was sich uns als das eigentlichste Wesen des Lebendigen darstellt. Wir können uns keinen Organismus denken ohne dieses Charakteristikum ${ }^{1}$ ).

Und nun kehren wir zuriick, und fragen uns: was will denn eigentlich der Darwinismus? Er will die Entstehung der or ganischen Zweckmässigkeit erklären. Das hiesse doch, el will die Entstehung des Lebens erklären. Aber will er demn das? Nein, sondern er setzt ja das Leben vora us und bringt nachträglich in die Organismenwelt die Zweckmässigkeit hinein. Er verlangt von uns, dass wir uns Organismen denken, welchen das Einzige fehlt, was wir als das Wesen des Organischen erkennen können. Der Darwinismus behauptet also, dass es Organismen gab, welchen die Eigenschaft der zweckmässigen Anpassung fehlte und für diese Behauptung bringt er nicht den leisesten Versuch eines Beweises, einer Begriindung, bringt ihn desshalb nicht, weil er gar nicht merkt, was er behauptet. Die Auf-

1) Wer sich überzeugt hat, dass die Besonderheit organischer Körper, ihr eigentliches Charakteristikum in der zweckmässigen Anpassung berubt, für den ist es eine völlig untergeordnete Frage, ob er dieser besonderen Fähigkeit organischer Körper auch einen besonderen Namen giebt. Er wird, wenn ihm dies bequem erscheint, durchaus kein Bedenken tragen, von einel vis adaptiva zu sprechen, weil er damit nur einer thatsächlich vorhandenen Erscheinung einen Namen giebt, und weil man ein Rätsel nicht dadurch aus der Welt schafft, dass man ängstlich vermeidet, es auszusprechen. 
gabe, den Beweis für diese Behauptung zu erbringen, d. h. diejenige Aufgabe, welche für den Darwinismus die allererste sein musste, ist ilm noch nicht einmal eingefallen, in Angriff zil nehmen.

Wir erkennen also, auf welchem Fundament das System des Darwinismus anfgebant ist. Lnd wir erkemnen, dass jede Erklärung, welche das Leben vor'ausset\%t, jede postritale Erklärung der organischen \%weckmässigkeit, in jedem Falle rolanssetzt, was sie erklären will; wir erkemen, dass die Frklärung der \%weckmässigkeit mit der Erklärumg des Lebens zusammenfallen mus.

Eine postritale Erklärung der Zweckmässigkeit ist anch der Lamarckismus. Er kam also ebentalls zur Löismg des hier in Frage stehenden Problems nichts beitragen. Anch uibersieht, was nur nebenbei bemerkt sein möge, der Lamarckismus vollständig, dass die Fähigkeit, durch Uebung zu gewinnen, eine äusser'st zweckmässige Einrichtung ist, die nicht zur Voranssetzung einer Erklärmg der Zweckmässigkeit gremacht werden darf. Der Lamarckismus hat mit dem Darwinismus cremeinsam, dass el ebenfalls versucht, seine .Tünger zu überrmpeln und ihnen die bittre Arznei der organischen \%weckmässigkeit in möglichst zahlreichen aber möglichst verdümnten Dosen einzugeben, in der Hoftinung, dass nichts davon gespuint wird, eine Ordinationsweise, die immer anf ein zallheiches und dankbares Publikun rechnen darf. Auch in der Fassung, welche Roux in seiner interessanten Schrift "Der Kampf der Teile im Organismus" dem Lamarckismus durch dessen Verbindung mit dem Selektionsprinzip gegeben hat, konnte dieser F'elıler; Weil el eben ein konstitutioneller ist, nicht beseitigt werden, ganz abgesehen davon, dass es zahlreiche Einrichtmgen giebt, für welche voll diesem Prinzip eine Erklärung verlangt werden miisste, ohne dass dasselbe eine solche zu leisten im stande sein kömnte. In der Schichtung der Linse unsres Auges haben wir z. B. die ebenso wunderbare Lösung einer MinimumNaximumaufgabe, wie in der Anordnung der Knochenbälkchen, 
zund doch kann hier selbstverständlich ron einer Erklärung durch funktionelle Anpassung keine Rede sein*).

Und selbst wenn wir einmal für eine Erscheinung der „äussern" oder der „innern"1) Zweckmässigkeit eine mechanische Entwicklungsweise nachgewiesen hätten, ja, sogar wenn dasjenige, was der sogenannten Entwicklungsmechanik als Ziel vorschwebt, vollständig erreicht wäre, so dïrften wir uns nicht verhehlen, dass damit für das eigentlich Biologische noch wenig gewonnen wäre. Selbst wenn wir den ganzen Organismus, alle seine Funktionen, zu denen auch seine Entstehung g’ehört, mechanisch verstünden, so hätten wir damit vom eigentlich Biologischen noch nichts verstanden. Wenn uns, frühern Beispiel zu bleiben, die Bewegungen sämtlicher Atome

*) Einen anderen Grundfehler der Lehre rom Kampf der Teile, nämlich die willkürliche Annahme, dass die funktionierenden Elemente auch die sich fortpflanzenden seien, habe ich in meiner Schrift „Der gegenwärtige Stand des Darwinismus" p. 21 angedeutet.

Eine ausführliche Widerlegung aller Darwinistischen Hilfshypothesen kann niemand verlangen. Sobald einmal das Ganze definitiv gefallen ist. werden diese Ersatzteile des Darwinismus, die jetzt mit einer geradezu komischen Wichtigkeit um's Dasein kämpfen, schon ron selbst verschwinden. Man könnte diesem Kampf der Teile sogar mit einem gewissen Behagcn zusehen, wenn nicht als Sieger aus demselben eine Kritiklosigkeit hervorginge, die nur mit Schlagwörtern um sich wirft. Mehr als jede andere Surrogattheorie des Darwinismus hat der „Kampf der Teile“ hierzu beigetragen. natürlich ohne Schuld ihres Autors, der sicherlich keine Freude empfindet. wenn er sieht, wie seine Theorie als inhaltslose Phrase verwendet wird, der aber gerade deshalb dem Fortschritt der Wissenschaft einen grossen Dienst erreisen könnte, wenn er durch eine erneute unbefangene und gründliche Prüfung seiner Theorie sich ron der Unrichtigkeit derselben überzeugen rürde.

1) Die ,innere" Zweckmässigkeit der ,äussern" gegenüberzustellen, ist prinzipiell unrichtig. Je höher der Organismus differenziert ist, $11 m$ so raffinierter kann el die Verhältnisse der Aussenwelt zu seinem Nutzen ausbeuten, um so ausgedehntere Vorarbeiten hat er anzustellen, um so kunstrollere Apparate in Betrieb zu setzen. So liefert die ,innere" Zreckmäissigkeit nur Vorarbeiten für äussere Leistungen, und ihr einziger L'uterschied ron der , „̈ussern" ist der, dass die Bezichungen zmr Aussenwelt nur indirekte sind. Das Gleiche gilt von der gegenseitigen Anpassung der Teile an einander und wler hieraus resultierenden, innern" Zweckmäissigkeit. 
mnd alle Kräfte bekamnt wären, welche zur Bildung des Kreuzschnabels fiuhren, so dass wir die Entstehung des Schnabels mechanisch vollständig verstïnden, so wäre uns das eigentlich Wesentliche noch eben so muerständlich als vorher. Denn das eigentliche biologische Rätsel ist ja die genane Beziehung dieses ganz bestimmten Schnabels zu dem ganz bestimmten Nadelbaumzapfen, und über diesen Punkt können wir von der Kenntnis derjenigen Kräfte, die bei der Ontogenese in Wirkung treten, also von der Entwicklungsmechanik, selbst wem sie auf dem Gipfel der Tollendung angelangt wäre, anch nicht die leiseste Aufklärung erwarten. Es ist deshalb auch keineswegs selbstverständlich und darf nicht einfach ohne Begrindung behauptet werden, dass von der Entwicklungsmechanik auch ..ein Schimmer der Auflellung auf die Ursachen der Phylogenese fallen" wird. Wenn wir z. B. über das Wesen der ontogenetischen Wiederhohmg phylogenetischer Prozesse etwas besser unterrich tet wären, wemn wir ,.die Kräfte, welche diese Wiederhohmg vollziehen" kennen würden, so wiirde uns damit ja noch nichts ïber diejenigen Kräfte bekannt sein, welche diese Prozesse in der Phylogenese hervorriefen. Ton der Kenntnis der ontogenetischen Kräfte einen Aufschluss ïber die plyylogenetischen ohne Weiteres als selbstverständlich zı erwarten, (sofern man nämlich sagen will, dass in diesem Punkt die Ontogenie sich anders verhalte wie jedes andere Kapitel. der Physiologie) wäre falsch nicht nur nach der im Obigen vertretenen Auffassung, sondern sogar vom Standpunkt des Darwinisten. Denn dass in der Entwicklung des einzelnen Individuums eine Zielstrebigkeit, ein Hinarbeiten auf ein bestimmtes Resultat ganz nuverkennbar ist, kann auch der Darwinist nicht leuguen. Eine solche Zielstrebigkeit soll aber in der Phylogenie fehlen. Die 'Zweckmässigkeit in der Ontogenese muss zugegeben werden, die, wenigstens primäre Zweckmässigkeit in der Plylogenese wird bestritten. Letzteres ist nun zwar falsch, doch allerdings besteht in diesem Punkte ein gewaltiger Unterschied zwischen beiden Arten der Entwicklung. Denn während wir einerseits in der Ontogenese einen fertigen zweckmässigen physiologischen T'organg beobachten, 
dessen Weg und Ziel gegeben ist, so ist andrerseits gerade das Erstaunliche an der phylogenetischen Entricklung, dass hier das Ziel gesucht, der Weg gefunden werden muss. Die Zreckmässigkeit der Ontogenese ist, wie die eines jeden physiologischen Vorgangs eine fertige, durch Vererbung ïberlieferte, wir sehen hier nur den Ablauf eines von langer Hand zweckmässig rolbereiteten Prozesses, der schon vorgezeichnet ist in der Organisation des Keimes. Die Frage nach dem eigentlich Wesentlichen, nach der wirklichen Entstehung dieser Zweckmässigkeit führt also zur Frage nach der Entstehung des Keimes und damit zur Phylogenese, während die Entwicklung aus dem Keime nur (wenn auch erklärende) Beschreibung des Vorgangs ergeben kann, ebenso wie die genaueste Physiologie der Niere nur eine Beschreibung zweckmässiger Vorgänge ist, in deren noch so genaner Darlegung eine Auskunft über das Zustandekommen dieser Vorgänge nicht gelegen sein kann. Wir sehen nur Ausgelöstes, durch Vererbung Ueberliefertes. Das erstmalige Auftreten einer Zweckmässigkeit sehen wir nicht, oder doch nur ansnahmsweise, unter abnormen Bedingungen und auch danm nicht anders wie auch auf andern physiologischen Gebieten. Dann handelt es sich aber eigentlich nicht um einen ontogenetischen, sondern eher um einen phylogenetischen Prozess. Alles, was in der Phylogenese nell auftrat, trat natuirlich im Lauf des Lebens von Individuen auf. Solche erstmaligen Erscheinungen, welche wir heute noch beobachten und als unsere wertvollsten Wegweiser ansehen kömnen, dürfen aber nur uneigentlich zur Ontogenie gerechnet werden, demn sie sind gänzlich verschieden von den durch Vererbung bestimmten Entwicklungsvorgängen, aus denen sich die eigentliche Ontogenese zusammensetzt. Die vorerwähnten erstmals auftretenden Erscheinungen könmen natürlich in jedem Abschnitt des individuellen Lebens (welches eigentlich in seiner Gesamtheit zur Ontog'enese gehört), also auch in der Ontogenese im engeren Simn auftreten, doch der Zeitpunkt, in welchem sie erscheinen, rerändert an und für sich nicht ihren Erklärungswert für die Phylogenese. Noch mehr gilt dies für die durch Vererbung fixierten 
ontogenetischen Prozesse, von denen die in ren Anfängen der Ontogenie auftretenden nur anf Grund einer Aeusserlichkeit, des formalen Momentes der Entstehnng, in besonder's nahe Beziehung zur Phylogenese gesetzt werden. Auch hier kommt der Zeitpunkt des individuellen Lebens, in welchem sie auftreten, für die Beziehmng zur Phylogenese nicht in Betracht, zu dieser verhält sich die Ontogenie (wenn man von den bei der $\mathrm{Be}$ schreibung der Vorgänge sich ergebenden Analogien absieht), nicht ander's, wie die andern, später auftretenden physiologischen Prozesse, und nicht mehr als diese kann sie prinzipiell zur Erklärung der Phylogenese beitragen.

Es ist durchans wichtig, sich diese Dinge klar zu machen, demn von den allgemeinen Gesichtspunkten hängt die Fragestellung spezieller Untersuchungen ab. Wir werden uns also nicht etwa ïberreden lassen, unsere Nengierde nach der ersten, d. h. phylogenetischen Entstehung von Zweckmässigkeiten so lange noch zu zïgehn, bis die Entwickelungsmechanik genügende Torarbeiten geliefert hat, sondern wir werden suchen, schon jetzt primäre Zweckmässigkeiten, d. h. Akte, in denen sich zum ersten Nale eine Zweckmässigkeit zeigt, anfznfinden. Z/u diesem Zweck ist es vor allem nötig, die Vererbung, welche die Ontogenie beherrscht, bei den Versuchen auszuschalten.

Schon seit einer Reihe von Jahren bin ich damit beschäftigt, von diesen Gesichtspunkten ansgehend, Experimente anzustellen, und es sei mir gestattet, die hauptsächlichsten Resultate einer diesbezügliehen Untersuchung hier vorläufig mitznteilen, deren ansfïhrliche Veröffentlichung baldigst elfolgen wird.

Um einen biologischen Vorgang zn finden, in welchen eine Zweckmässigkeit primär, d. l. nicht als ererbte auftritt, versuchte ich, dem Amphibien-Auge die Linse herauszunehmen, um zu sehen, wie das Tier darauf reagiere. Es war von vornherein wahrscheinlich, dass der Wassersalamander, dieser klassische Repräsentant des Regenerationsvermögens unter den Wirbeltieren, den Verlust der Linse in irgend einer zweckmässigen Weise kompensieren werde, so dass mit ziemlicher 
Sicherheit aus diesem Versuch für unsere Frage etwas zu hoffen war, ganz besonders im Hinblick auf die etwaige Möglichkeit völliger Regeneration der Linse. Denn wenn diese erfolgte, so konnte sie ja unmöglich nach dem ererbten Typus der ontogenetischen Entstehung erfolgen, sondern der Organismus musste völlig neue Weg'e finden, um dieses Gebilde wieder herzustellen. welches, losgelöst von seinem Mutterboden, als ein Fremdling in fremde Umgebung gewandert und mit dieser nur in ganz lockere, äusserliche Verbindung getreten war. Der Versuch zeigte, dass die der Larve und der erwachsenen Form ron Triton taeniatus entnommene ${ }^{1}$ ) Linse nach einigen Monaten vollständig regeneriert ist. Nach Feststellung dieses Thatbestandes war zu ermitteln, auf welchem Wege die Regeneration erfolgt. Als das Wahrscheinlichste konnte vielleicht zunächst erachtet werden die Regeneration aus dem Corneaepithel, weil dieser Weg der ontogenetischen Entstehung am nächsten käme. Bedachte man jedoch, dass in diesem Falle die Epithelzellen die ganze mesodermale Schicht der Cornea, die vordere Kammer und die Pupillaröffnung zu durchwandern hätten, so komnte diesem Entstehungsmodus wenig Wahrscheinlichkeit zugesprochen werden; es war vielmehr zu vermuten, dass die Regeneration erfolge aus Zellen des Augenbechers oder seines Inhalts. Aber was sind denn da noch für Zellen, an welche man denken könnte? Etwa die Retinazellen? Diese waren von vornherein auszuschliessen: so hochdifferenzierte Zellen können sich nicht mehr zum einfachen Epithel zurïckbilden. Oder etwa mesodermale Zellen? Dass Bindegewebszellen, welche ja urspriinglich selbst Epithelzellen waren, sich wieder zum epithelialen Verbande ordnen, ist ja in der Embryologie nichts Unerhörtes. Aber doch war die mesodermale Regeneration eines ektodermalen Gebildes kaum zu erwarten. Doch was konnte denn sonst noch in Betracht kommen? Etwa das Epithel der Iris? Sollten Zellen, welche den Beruf haben und bereits ausüben, möglichst un-

1) Medianer Schnitt durch die Cornea, Entbindung durch rorsichtigen Druck auf den Bulbus. 
durchsichtig zu sein, diesen Beruf auch einmal, wenn es gerade zweckmässig ist, vertauschen können mit dem denkbar entgegengesetztesten Berufe, möglichst durchsichtig' zn sein: Jedenfalls haben wir hier ein ektodermales Epithel, welches den Epithelcharakter des urspriunglichen Hornblattes, aus welchem ontogenetisch die Linse entsteht, noch am reinsten bewahrt hat. Die einzige Differenzierung desselben ist die dichte Pigmentanhäufung in den Zellen. Aber die Wegschaffing ron Pigment ist für den Organismus bekamntlich eine Kleinigkeit. Die Linse aus diesem Epithel zu regenerieren, musste für den Organismus unter allen rorhandenen der einfachste Weg sein. Und diesen einfachsten Weg wählt der Organismus. Das innere epitheliale Blatt der Iris verliert sein Pigment. welches von massenhaft herbeieilenden Lenkocyten fortgetragen wird, am Pupillarrande wuchert das Epithel, aus diesen Wucherungen entsteht am obern Rand der Pupille ein Linsensäckchen. und aus diesem Jinsensäckchen bildet sich - nummehr nach vererbtem 'lypus - die vollständig normale 'L'ritonenlinse.

Dieser Vorgang der Linsenregeneration, den ich an andrer' Stelle ${ }^{1}$ ) ausführlich beschrieben habe; und dessen Richtigkeit durch Nachuntersuchung ron andrer Seite in allen Einzelheiten bestätigt wurde, ist zweifellos eine Erscheinung; in der uns die nicht ererbte, also primär ' '/weckmässigkeit mit einer Klar'heit sich offenbart, welcher kein Zurechmungsfähiger sich verschliessen kann. Und es ist mit dieser direkten Darlegung der primären Zweckmässigkeit wohl auch der Beweis erbracht, dass die teleologische Fragestellung nicht, wie ilı hänfig rorgeworfen wird, eine unfruchtbare, den Fortschritt hemmende. ist, sondern dass sie, abgesehen davon, dass sie die einzige ist, die den 'Thatsachen Rechnung trägt, heuristischen Wert besitzt. Natürlich komnte die Thatsache der Linsenregeneration auch auf andre Weise gefunden werden. Wenn z. B. jemand auf den Einfall geriet, einen Triton herzunehmen und successive ron ihm abzuschneiden, was abzuschneiden ist, und die Regeneration

1) Archir f. Entwickelungsmechanik Band I p. $3 S(1) \mathrm{ff}$. 
zu studieren, so hätte schliesslich auch einmal die Linse an die Reihe kommen und ihre Regeneration ,entdeckt" werden können. Dies wäre damn zwar keine wissenschaftliche Entreckung gewesen, sondern nur ein zufälliger Fund, der allerdings, wenn der Finder seine Bedentung erkannte, die entsprechende wissenschaftliche Verwertung finden konute. Von ganz besonderem Interesse ist es daher, dass, nachdem meine Entdeckung längst bekannt war und allgemeine Verwunderung erregt hatte, es sich herausstellte, dass diese Linsenregeneration schon frïher als zufälliger Fund von einem Italiener beobachtet ${ }^{1}$ ) und beschrieben worden war. Colucci untersuchte die Regeneration aller Augenteile bei Triton und musste daher natürlich auch auf die Regeneration der Linse stossen. Er hat aber die Bedeutung seines Fundes nicht im geringsten erkannt, weil sein biologisches Denken allzusehr an doktrinäre. Schulbegriffe gebunden war. So fest war bei ihm der Glaube an die Realität systematischer Schulformeln, dass er ausdrïcklich darauf hinweisen konnte, die embryonale und die regenerative Entwicklung der Linse biete keine prinzipielle Verschiedenheit, weil ja in beiden Fällen die Linse vom - Ektoderm geliefert wird!!

Die "Priorität" Coluccis ist also dahin zu präzisieren, dass er zufällig eine 'Thatsache von fundamentaler biologischer' Bedeutung gefunden, dass er dieselbe aber, weil er diese Bedeutung nicht im mindesten erkannte, nicht an den ihr gebührenden Platz gestellt, sondern mit seinen übrigen prinzipiell unbedeutenden Beobachtungen in ein en Topf zusammengeworfen hat, aus dem sie nun erst nachträglich wieder hervorgeholt werden konnte. Aber in Bezug auf dasjenige, was die Linsenregeneration zu einer biologisch wichtigen Thatsache macht, hat Colucci keine Priorität zu beanspruchen, und ob ihm somit in dieser Sache ein wissenschaftliches Verdienst zukommt, braucht wohl nicht mehr erörtert zu werden.

1) Colucei, Sulla rigenerazione parziale dell' occhio nei Tritoni. Memorie della R. Accad. d. scienze, Bologna 1890, Ser. V, Tom. I. Der strikte Beweis für die Regeneration aus der Iris ist allerdings in der knappen Coluceischen Darstellung nicht enthalten. 
Die Kenntnis ron Coluccis "Prioritït" verdanken wir Emery und es ist durch dessen Mitteilung ${ }^{1}$ ) die noch viel interessantere, fast unglaubliche, aber für unsere biologischen Verhältnisse höchst charakteristische Thatsache ans Licht gekommen, dass ein Schriftsteller, der fortwährend ïber die höchsten biologischen Fragen Abhandlungen schrieb, und der mit seinen "Gedanken“ uiber Darwinismus und Abstammung'slehre Beachtung fand, Kenntnis von der T'hatsache der Linsenregeneration hatte, dieselbe aber in jenen zahlreichen Abhandlungen mit keiner silbe er'wähnt lıat ${ }^{2}$ ).

1) Anatom. Anzeiger Band XIII p. (i:). Emery hat nicht num gregen mich, sondern sogar gegen Erik Müller, der doch mm eine Nachprüfung vornahm, den Verdaeht des Plagiats alugesprochen; er hat also nachwoislich wider besseres Wissen jemanden des Diehstahls rerdächtigt.

๖) Wollte mau naeh Emerys Manier vorgehen, so kömute man ihn verdïehtigen, diese für den Darwinismus so unbequene Thatsache in jenen Abhandlungen absichtlieh verschwiegen zu haben. Ich kemne jedoch Emery„Gedanken“" zu genau, als dass ich nicht in Tezng anf diesen Punkt ron seiner Ehrlichkeit vollständig überzeugt wäre. 
R. b. Hof- u. Univ.-Buchdruckerei Fr. Junge (Junge \& Sohn). Erlangen. 